\title{
Exploring the Anti-Hypertensive Properties of Medicinal Plants and Their Bioactive Metabolites: An Extensive Review
}

\author{
Md. Moaz Ahmed Asif ${ }^{1 *}$, Susmita Roy Lisa ${ }^{1 *}$, Nazmul Qais ${ }^{2 \#}$ \\ ${ }^{1}$ Department of Pharmaceutical Chemistry, Faculty of Pharmacy, University of Dhaka, Dhaka, Bangladesh \\ ${ }^{2}$ Department of Clinical Pharmacy and Pharmacology, Faculty of Pharmacy, University of Dhaka, Dhaka, Bangladesh \\ Email:"nqais@du.ac.bd
}

How to cite this paper: Asif, Md.M.A., Lisa, S.R. and Qais, N. (2021) Exploring the Anti-Hypertensive Properties of Medicinal Plants and Their Bioactive Metabolites: An Extensive Review. American Journal of Plant Sciences, 12, 1705-1740.

https://doi.org/10.4236/ajps.2021.1211119

Received: October 6, 2021

Accepted: November 27, 2021

Published: November 30, 2021

Copyright $\odot 2021$ by author(s) and Scientific Research Publishing Inc. This work is licensed under the Creative Commons Attribution International License (CC BY 4.0).

http://creativecommons.org/licenses/by/4.0/

(c) (i) Open Access

\begin{abstract}
Medicinal plants are extensively used in traditional folk medicine. High blood pressure is associated with the risk of cardiovascular diseases (CVDs) and many other serious health complications resulting from it as a major concern of morbidity and mortality in health sector. Use of diuretics, angiotensin converting enzyme (ACE) inhibitors, beta adrenergic receptor antagonists (beta blockers), alpha adrenergic receptor antagonists (alpha blockers), calcium channel blockers (CCBs) etc. are not efficient enough to cure hypertension. Side effects regarding these medications lead to intolerance, impaired control of the disease, and also mismanagement of therapy. So, approach regarding quenching new potent therapeutic compounds from medicinal plants draws attention nowadays. For example, as a first-line therapeutic agent, an alkaloid is highly effective in lowering systolic blood pressure which is isolated from root extract of the plant of Rauwolfia serpentina species, namely reserpine. This article comes up with a list of 63 plant species from 37 families, compiling information related to plant parts used for making extracts, types of extract and animals used in these studies, antihypertensive effect of the extracts etc. It also refers to 74 chemically defined molecules, with in vitro and in vivo anti-hypertensive potential, isolated from these extracts along with their dosage and mechanism of action by using electronic searches of published articles from various databases and reference books. Our present work would be beneficial for researchers to investigate and invent novel antihypertensive therapy to treat hypertension.
\end{abstract}




\section{Keywords}

Hypertension, Anti-Hypertensive, Phytoconstituents, Medicinal Plants, Angiotensin Converting Enzyme, Nitric Oxide

\section{Introduction}

The definition of hypertension (HTN) is when office systolic blood pressure (SBP) and/or diastolic blood pressure (DBP) is equal or greater than $140 \mathrm{mmHg}$, and $90 \mathrm{mmHg}$ respectively [1]. HTN is often called "the silent killer". If HTN is left untreated, end organ damage may occur [2]. People with elevated blood pressure (BP) may face some major risk of being affected by coronary artery disease with the following complications e.g., blindness in diabetic patients, heart failure, renal diseases, and stroke [3]. 972 million people had HTN in 2000 and this number was predicted to be about 1.56 billion in 2025 [4]. Obesity, unhealthy diet, tobacco use, physical inactivity, and HTN are some factors that increase the risk of CVDs [5]. Reducing SBP by $5 \mathrm{mmHg}$ is shown to lower mortality rate by $9 \%, 14 \%$, and $7 \%$ respectively for coronary heart disease, stroke, and in total [6].

Until now, there are different antihypertensive therapies available, such as: ACE (classified as EC3.4.15.1) inhibitors, angiotensin receptor blocker (ARB), beta blockers, diuretics, and also CCBs [7] [8]. They show their antihypertensive effect by controlling cardiac output (CO) (affecting stroke volume and heart rate), and peripheral or systemic vascular resistance.

Impairment in production of nitric oxide (NO) is a very common reason behind endothelial dysfunction, which leads to HTN [9] [10]. Figure 1 shows that, endothelial NO synthase (eNOS) produces NO from L-arginine in the blood vessels to control cardiovascular function [11]. High BP was induced due to chronic blocking of $\mathrm{NO}$ after administrating $\mathrm{N} \omega$-Nitro-l-arginine methyl ester (1-NAME) depending upon dose and time [12]. 1-NAME contributes to endothelial dysfunction in resistant vessels by decreasing metabolites of NO present in plasma and downregulating expression of eNOS protein [13].

Oxidative stress also promotes HTN pathogenesis [15]. In a rat model of NO depletion-induced hypertension, excess reactive oxygen species (ROS) and declined amount of endogenous antioxidant enzymes have been found [16]. High amount of vascular superoxide $\left(\mathrm{O}_{2}^{-}\right)$, malondialdehyde (MDA), and plasma protein carbonyl were found in $\mathrm{NO}$ deficient hypertensive rats [17] [18]. $\mathrm{O}_{2}^{-}$ quenches $\mathrm{NO}$ to produce peroxynitrite $\left(\mathrm{ONOO}^{-}\right)$directly and decreases $\mathrm{NO}$ bioavailability [19].

Again, 1-NAME causes overproduction of ROS and activates the renin-angiotensin system (RAS) [20] [21]. Angiotensin II (Ang-II) is a potential vasoconstrictor and for that as shown in Figure 2, RAS is a compulsory factor in pathogenesis of HTN [22]. Renin is released by renal artery constriction and Ang-II 


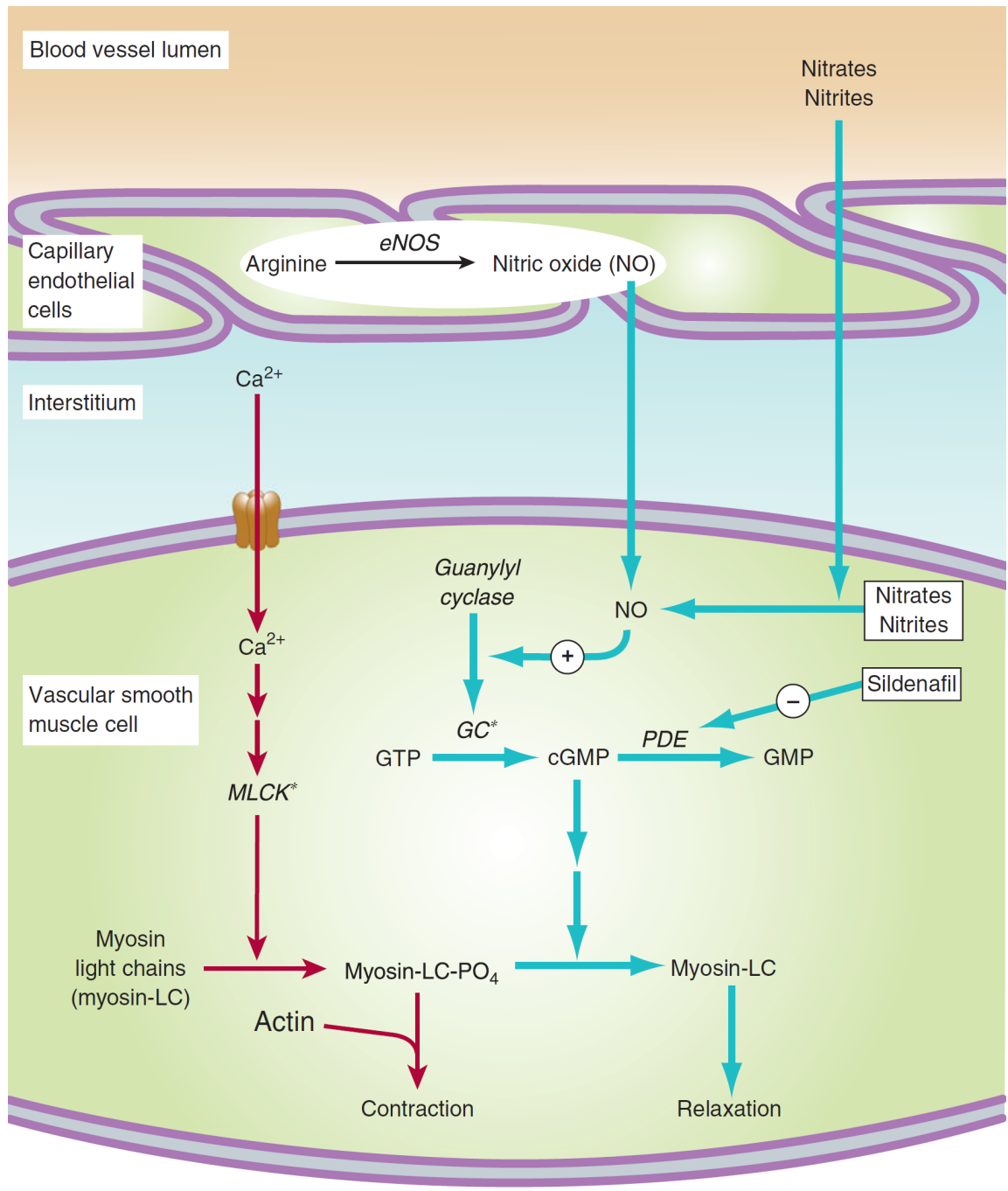

Figure 1. The mechanism of action of Nitrates, and nitrites that increase NO in vascular smooth muscle cells (VSMC). Steps producing vascular contraction are presented with red arrows, and those causing vascular relaxation are displayed with blue arrows [14]. $\mathrm{MLCK}^{*}=$ activated myosin light-chain kinase; $\mathrm{GC}^{\star}=$ activated guanylyl cyclase or guanylate cyclase; $\mathrm{PDE}=$ phosphodiesterase.

production is increased by activating RAS in NO deficient hypertensive rats [23] [24]. In l-NAME treated rats, Ang-II stimulates the Ang-II type 1 receptor $\left(\mathrm{AT}_{1} \mathrm{R}\right)$ which produces $\mathrm{O}_{2}^{-}$activated by nicotinamide adenine dinucleotide phosphate (NADPH)-oxidase [13]. Elevated ACE, cardiac and plasma Ang-II, and $\mathrm{AT}_{1} \mathrm{R}$ expression also confirmed RAS stimulation in those above-mentioned rats [25].

RAS is also a vital factor because chronic NO inhibition results in arterial remodeling and $\mathrm{AT}_{1} \mathrm{R}$ blockers prevent that [26]. Vascular remodeling occurs by Ang-II binding to $\mathrm{AT}_{1} \mathrm{R}$ and activating serine/threonine kinase (Akt), one of its own intracellular downstream signaling protein responsible for Ang-II driven proliferation in VSMC [27]. Signal transducers and activators of transcription protein get phosphorylated by Janus kinases induced by $\mathrm{AT}_{1} \mathrm{R}$ activation that causes vascular proliferation and remodeling [28]. 


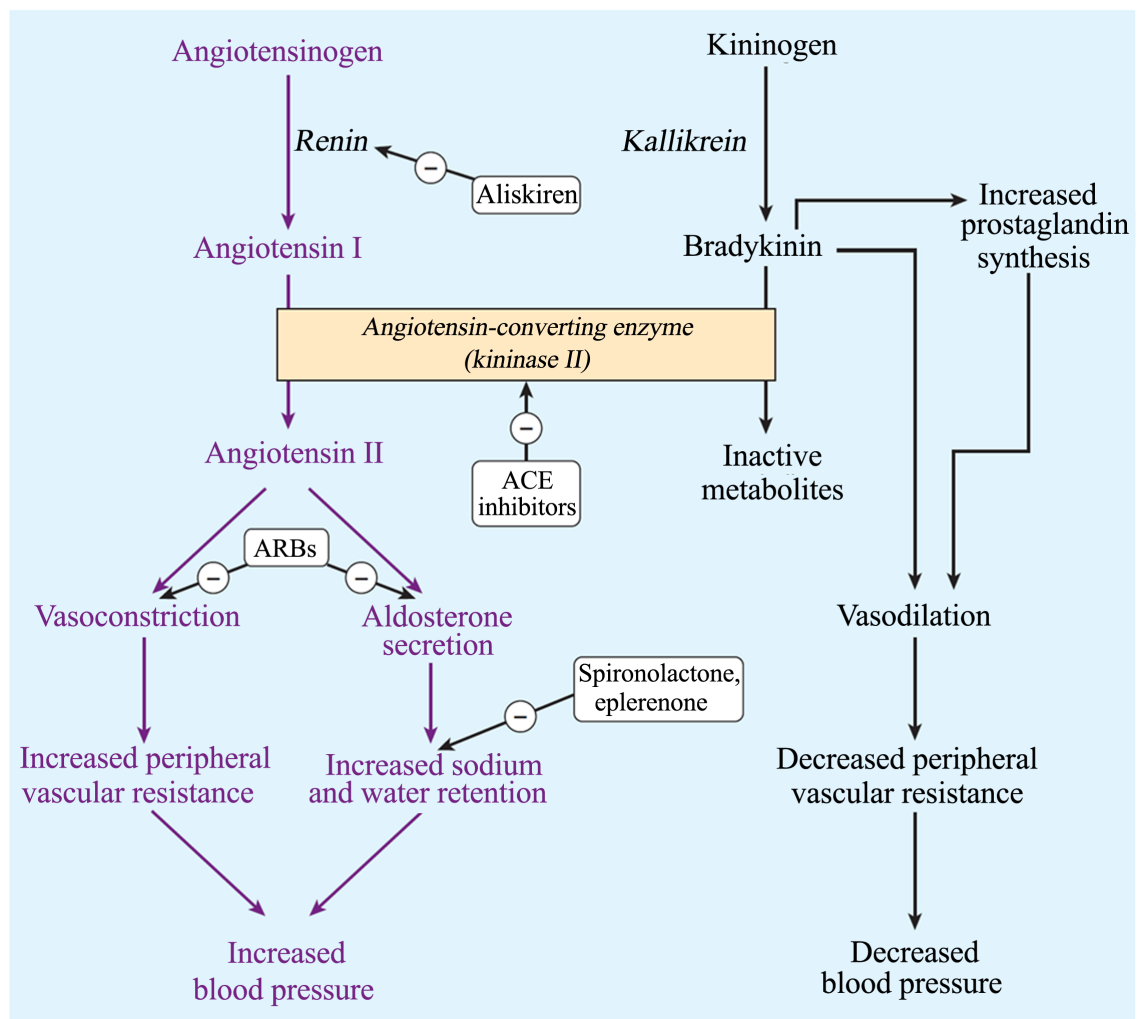

Figure 2. Sites of action of drugs that interfere with the RAS, also known as the renin-angiotensin-aldosterone system (RAAS) [14].

Despite using these agents, many patients cannot control their high BP [29]. HTN cannot be effectively managed in about $30 \%$ of the patients who comply with prescription therapies [30]. The available antihypertensive agents are not successful in all the cases along with disease severity [31]. These agents are categorized as combination therapy, costly and their ambiguous regimen of cure decreases drug adherence and may also surge adverse effects as well as drug interactions [32]. Among these, ACE inhibitors cause bronchospasm and cough [33]; ACE inhibitors and CCBs can cause angioedema with upper respiratory tract obstruction [34]; CCBs also increase the risk of cancer by inhibiting the growth of vascular cells and angiogenic growth factors due to increasing apoptosis [35]; beta blockers induce side effects related to central nervous system [36]. Dyspnea, headache, edema, cough, hair loss, and flushes are also reported as side effects of antihypertensive drugs [37]. So, the acceptance of alternative therapy is increasing day by day, as natural herbal products using medicinal plants show fewer side effects [38]. Numerous of them have the potential for therapy of CVDs including, HTN, arrhythmia, and venous insufficiency [39].

The goal of our work is to accumulate various phytoconstituents that exhibit in vitro and in vivo antihypertensive effects so that they can be used to make safe, patient-adhered, low-cost antihypertensive therapy with preferable minimum side effects. Combination of these natural compounds can also be therapeutic as more than one compound, responsible for antihypertensive effect, are 
often found in extracts. Our review includes 63 species of plants from 37 family, plant parts used for making extracts, types of extract and animals used for these experiment, antihypertensive effect of the extracts as well as 74 confirmed antihypertensive compounds isolated from these extracts with their dosage and mechanism of action.

\section{Discussion about Promising Anti-Hypertensive Plants}

Herbal medicine is a tremendous source for seeking out novel therapeutic compounds for numerous diseases. The idea of generating medicine from scratch had originally come out from the traditional uses of herbs and plants by our fellow ancestor to cure many of their ailments. Herbal medicines are quite preferable among people for its significantly low side effects and also the belief regarding nature made.

Traditional use of some plants like Cocos nucifera Linn (Arecaceae), Curcuma domestica (Zingiberaceae), Terminalia bellerica Roxb. (Combretaceae) etc. are well known for treating HTN. Aim of this article is highlighting and compiling the data regarding chemo-profiles, pharmacology of various plant species used to treat HTN. Information regarding plant species is collected from online resources and journals such as PubMed, Google Scholar, SciFinder, ScienceDirect and so on. Table 1 illustrates a comprehensive overview of phytoconstituents, dosage, use, extracts of potential medicinal plants with prominent anti-hypertensive activity.

Among the described compounds, we think four of the compounds were therapeutically efficient. The first one, tilianin which is derived from Agastache mexicana, demonstrated dose-dependent anti-hypertensive effects, with an $\mathrm{ED}_{50}$ of $53.51 \mathrm{mg} / \mathrm{kg}$ which was lower than the $\mathrm{LD}_{50}$ of $6624 \mathrm{mg} / \mathrm{kg}$, offers a wide spectrum of pharmacology responses. In addition, this study provides evidence about safety and efficacy of tilianin as antihypertensive agent, as well as, claims of no damage at physiologic, functional and cellular levels in rodent models [41]. The next one is naringenin, isolated from Cochlospermum vitifolium, exhibit a statistically significant dose-dependent decay on SBP (control: $184.00 \mathrm{mmHg}$ vs. sample: $154.93 \mathrm{mmHg}$ ) after $24 \mathrm{~h}$ post-administration at $50 \mathrm{mg} / \mathrm{kg}$, and also, a significant decrease of SBP (control: $184.00 \mathrm{mmHg}$ vs. sample: $142.64 \mathrm{mmHg}$ ) and DBP (control: $159.62 \mathrm{mmHg}$ vs. sample: $122.05 \mathrm{mmHg}$ ) at $160 \mathrm{mg} / \mathrm{kg}$ [55]. Curcumin nanoemulsion is our favorite choice, prepared from Curcuma domestica and having a $71.166 \%$ inhibition (after corrections) on HMGCR (a liver enzyme that contributes to cholesterol synthesis) to assess antihypercholesterolemic activity when compared to pravastatin. Curcumin:

1) Inhibits hepatic HMG-CoA activity and lowers HMGR gene expression (that produces the HMG-CoA enzyme).

2) Suppresses triglyceride and cholesterol accumulation in the liver due to its antihyperlipidemic properties.

3) Enhances PPAR $\alpha$ gene expression that regulates fatty acid oxidation. 
Md. M. A. Asif et al.

Table 1. Anti-hypertensive plant species with isolated phytochemicals and their mechanism of action.

\begin{tabular}{|c|c|c|c|c|c|c|}
\hline $\begin{array}{l}\text { Plant } \\
\text { (Family) }\end{array}$ & $\begin{array}{l}\text { Plant Parts, } \\
\text { Type of } \\
\text { extract }\end{array}$ & $\begin{array}{l}\text { Animal } \\
\text { used }\end{array}$ & $\begin{array}{l}\text { Isolated } \\
\text { Antihypertensive } \\
\text { Phytochemicals }\end{array}$ & $\begin{array}{l}\text { Use and } \\
\text { Dosage }\end{array}$ & $\begin{array}{l}\text { Mechanism } \\
\text { of action }\end{array}$ & Citation \\
\hline $\begin{array}{l}\text { Acanthopanax } \\
\text { sessiliflorus } \\
\text { (Araliaceae) }\end{array}$ & $\begin{array}{l}\text { Fruits, } \\
\text { Ethanolic } \\
\text { extract }\end{array}$ & $\begin{array}{l}\text { Male } \\
\text { Wistar } \\
\text { rats }\end{array}$ & $\begin{array}{l}\text { 3(a) } 22 \alpha \text { - } \\
\text { hydroxychiisanoside } \\
\text { 3(b) } 22 \alpha \text { - } \\
\text { hydroxychiisanogenin } \\
\text { 3(c) chiisanoside } \\
\text { 3(d) chiisanogenin } \\
\text { 3(e) momordin Ib } \\
\text { (Figure 3) }\end{array}$ & $\begin{array}{l}\text { In vivo } \\
\text { antithrombotic } \\
\text { and antiplatelet } \\
\text { activities. } \\
125,250,500 \\
\text { and } \\
1000 \mathrm{mg} / \mathrm{kg} / \text { day. }\end{array}$ & $\begin{array}{l}\text { Ethanolic extracts } \\
\text { from } A \text {. sessiliflorus } \\
\text { showed effects by } \\
\text { 1) scavenging free } \\
\text { radical } \\
\text { 2) NO production } \\
\text { facilitation } \\
\text { 3) inhibition of ACE }\end{array}$ & {$[40]$} \\
\hline $\begin{array}{l}\text { Agastache } \\
\text { mexicana } \\
\text { (Lamiaceae) }\end{array}$ & $\begin{array}{l}\text { Aerial parts, } \\
\text { Methanolic } \\
\text { extracts and } \\
\text { EtOH: } \mathrm{H}_{2} \mathrm{O} \\
\text { (7:3) extracts }\end{array}$ & $\begin{array}{l}\text { Male } \\
\text { Wistar } \\
\text { rats }\end{array}$ & $\begin{array}{l}3(\mathrm{f}) \text { tilianin } \\
\text { (Figure } 3 \text { ) }\end{array}$ & $\begin{array}{l}\text { Vasorelaxant } \\
\text { activity. } \\
12.5,25,75, \\
100 \mathrm{mg} / \mathrm{kg} . \\
6624 \mathrm{mg} / \mathrm{kg} \text { is the } \\
\text { lethal dose. }\end{array}$ & $\begin{array}{l}\text { Tilianin isolated from } \\
\text { methanolic extract of } \\
\text { A. mexicana exhibited } \\
\text { endothelium-dependent } \\
\text { vasorelaxant effect by } \\
\text { 1) NO production } \\
\text { and } \\
\text { 2) opening } \mathrm{K}^{+} \text {channel }\end{array}$ & {$[41]$} \\
\hline $\begin{array}{l}\text { Allanblackia } \\
\text { floribunda } \\
\text { Oliv. } \\
\text { (Clusiaceae) }\end{array}$ & $\begin{array}{l}\text { Bark, } \\
\text { Aqueous } \\
\text { extract. }\end{array}$ & $\begin{array}{l}\text { Sucrose- } \\
\text { induced } \\
\text { hypertensive } \\
\text { rats (SuHR), } \\
\text { Alcohol- } \\
\text { induced } \\
\text { hypertensive } \\
\text { rats (AHR) }\end{array}$ & Not reported & $\begin{array}{l}\text { Prevention of HTN } \\
\text { in rats induced by } \\
\text { alcohol, sugar, } \\
\text { and also oxidative } \\
\text { stress. } \\
\text { Aqueous extract } \\
\text { of } 200 \text { and } \\
400 \mathrm{mg} / \mathrm{kg} / \text { day. }\end{array}$ & $\begin{array}{l}\text { Extract of } \\
\text { A. floribunda Oliv. } \\
\text { significantly impeded } \\
\text { 1) the upsurge of MDA, } \\
\text { superoxide dismutase } \\
\text { (SOD), catalase } \\
\text { 2) the decrease of } \\
\text { glutathione in kidney, } \\
\text { liver, aorta, and heart } \\
\text { of SuHR and AHR. }\end{array}$ & {$[42]$} \\
\hline $\begin{array}{l}\text { Alstonia } \\
\text { scholaris } \\
\text { (Apocynaceae) }\end{array}$ & $\begin{array}{l}\text { Bark and leaves, } \\
\text { Methanol } \\
\text { extract, } \\
\text { dichloromethane } \\
\text { fraction, ethyl } \\
\text { acetate fraction } \\
\text { and n-butanol } \\
\text { fraction, }\end{array}$ & $\begin{array}{l}\text { Sprague } \\
\text { Dawley rats }\end{array}$ & Not reported & $\begin{array}{l}\text { Vasorelaxant } \\
\text { activity. } \\
0.5,1 \text { and } 2 \\
\mathrm{mg} / \mathrm{mL} \text {. }\end{array}$ & $\begin{array}{l}\text { Prepared extracts from } \\
\text { A. scholaris possess } \\
\text { vasodilation by } \\
\text { 1) blocking } \mathrm{Ca}^{2+} \text { channels } \\
\text { 2) soluble guanylate } \\
\text { cyclase (sGC) direct } \\
\text { activation } \\
\text { 3) inhibition of inositol } \\
\text { 1,4,5-triphosphate } \\
\text { formation }\end{array}$ & {$[43]$} \\
\hline $\begin{array}{l}\text { Apium } \\
\text { graveolens } \\
\text { (Apiaceae) }\end{array}$ & $\begin{array}{l}\text { Plant materials, } \\
\text { Hexane, } \\
\text { dichloromethane, } \\
\text { ethyl acetate and } \\
\text { methanol } \\
\text { extracts }\end{array}$ & $\begin{array}{l}\text { Male } \\
\text { Wistar } \\
\text { rats }\end{array}$ & $\begin{array}{l}3(\mathrm{~g}) \text { apigenin } \\
\text { (Figure } 3 \text { ) }\end{array}$ & $\begin{array}{l}\text { Vasorelaxant } \\
\text { activity. } \\
62,110 \text { and } \\
200 \mu \mathrm{g} / \mathrm{mL} \\
\text { (ethyl acetate } \\
\text { extract). }\end{array}$ & $\begin{array}{l}\text { Extracts of } A \text {. graveolens } \\
\text { exerts vasodilation by } \\
\text { interfering with } \\
\text { 1) voltage-dependent } \\
\mathrm{Ca}^{2+} \text { channels (VDCC) } \\
\text { 2) receptor-operated } \\
\mathrm{Ca}^{2+} \text { channels (ROCC). }\end{array}$ & {$[44]$} \\
\hline $\begin{array}{l}\text { Areca } \\
\text { Catechu L. } \\
\text { (Arecaceae) }\end{array}$ & $\begin{array}{l}\text { Seed, } \\
\text { Areca II-5-C }\end{array}$ & $\begin{array}{l}\text { Male } \\
\text { Spontaneous } \\
\text { Hypertensive } \\
\text { Rats (SHR) }\end{array}$ & Not reported & $\begin{array}{l}\text { Antihypertensive } \\
\text { effects, } 100 \text { and } \\
200 \mathrm{mg} / \mathrm{kg} \\
\text { comparable with } \\
30 \text { and } 100 \mathrm{mg} / \mathrm{kg} \\
\text { of captopril. } \\
10 \text { and } 15 \mathrm{mg} / \mathrm{kg} \text { (IV). }\end{array}$ & $\begin{array}{l}\text { Inhibitory hypertensive } \\
\text { effect of } A \text {. catechu } \\
\text { specially Areca II-5-C is } \\
\text { mediated by the } \\
\text { 1) inhibition of } \\
\text { pressor responses } \\
\text { to both Angiotensin I } \\
\text { and Ang-II. }\end{array}$ & {$[45]$} \\
\hline
\end{tabular}




\section{Continued}

\begin{tabular}{|c|c|c|c|c|c|c|}
\hline $\begin{array}{l}\text { Artemisia } \\
\text { campestris } \mathrm{L} \\
\text { (Asteraceae) }\end{array}$ & $\begin{array}{l}\text { Aerial part, } \\
\text { Aqueous } \\
\text { extract (AcAE) }\end{array}$ & $\begin{array}{l}\text { Wistar rats } \\
\text { and Albino } \\
\text { mice }\end{array}$ & $\begin{array}{l}\text { 3(h) chlorogenic acid } \\
3(\mathrm{i}) 3,4- \\
\text { dicaffeoylquinic acid } \\
3(\mathrm{j}) 3,5- \\
\text { dicaffeoylquinic acid } \\
\text { 3(k) } 4,5- \\
\text { dicaffeoylquinic acid } \\
\text { 3(l) vicenin-2 } \\
\text { (Figure 3) }\end{array}$ & $\begin{array}{l}\text { Antihypertensive, } \\
\text { hypotensive and } \\
\text { vasorelaxant } \\
\text { effect. } \\
40,150 \mathrm{mg} / \mathrm{kg} / \text { day. }\end{array}$ & $\begin{array}{l}\text { Aqueous extract (AcAE) } \\
\text { of } A \text {. campestris exerts } \\
\text { hypotensive, } \\
\text { antihypertensive, and } \\
\text { vasorelaxant effect by } \\
\text { 1) calmodulin-NO-cGC- } \\
\text { PKG pathway } \\
\text { 2) } \mathrm{Ca}^{2+} \text { influx inhibition } \\
\text { through volage-operated } \\
\text { calcium channels (VOCC) } \\
\text { 3) intracellular } \mathrm{Ca}^{2+} \\
\text { mobilization activation } \\
\text { into sarcoplasmic reticulum }\end{array}$ & [46] \\
\hline $\begin{array}{l}\text { Berberis } \\
\text { vulgaris } \\
\text { (Berberaceae) }\end{array}$ & $\begin{array}{l}\text { Roots, } \\
\text { Ethanolic extract }\end{array}$ & $\begin{array}{l}\text { Not } \\
\text { reported }\end{array}$ & $\begin{array}{l}3(\mathrm{~m}) \text { berberine } \\
\text { (Figure } 3 \text { ) }\end{array}$ & $\begin{array}{l}\text { In vitro antioxidant } \\
\text { effect. } \\
0.2-1 \mathrm{mg} / \mathrm{ml} \\
\text { extract decreased } \\
\text { production of } \\
\text { thiobarbituric acid } \\
\text { reactive substances } \\
\text { (TBARS) from } \\
9 \pm 0.3 \text { to } \\
4 \pm 1.1 \mathrm{nmol} / \mathrm{g} \text {. } \\
0.2-1 \mathrm{mg} / \mathrm{ml} \text { extract } \\
\text { and berberine } \\
\text { lowered NO, } \\
2,2-\text { diphenyl-1- } \\
\text { picrylhydrazyl (DPPH) } \\
\text { oxidation in the range } \\
\text { of } 16 \% \text { - } 25 \% \text { and } \\
13 \%-46 \% \text { than } \\
\text { control respectively } \\
\text { (p < } 0.05 \text { ); increased } \\
\text { liver glutathione } \\
\text { peroxidase and SOD } \\
\text { activity in the range } \\
\text { of } 10 \% \text { - } 70 \% \text { and } \\
55 \% \text { - } 270 \% \\
\text { respectively. }\end{array}$ & Not reported & [47] \\
\hline $\begin{array}{l}\text { Calpurnia aurea } \\
\text { (Ait.) } \\
\text { (Fabaceae) }\end{array}$ & $\begin{array}{l}\text { Seed, } \\
80 \% \text { methanol } \\
\text { extract }\end{array}$ & $\begin{array}{l}\text { Sprague- } \\
\text { Dawley rats, } \\
\text { Guinea pigs }\end{array}$ & Not reported & $\begin{array}{l}\text { Hypotensive and } \\
\text { antihypertensive } \\
\text { effects, } 5-250 \mathrm{mg} / \mathrm{L} \text { of } \\
80 \% \text { methanol extract, } \\
\text { maximum } 92.1 \% \\
\text { relaxation achieved } \\
\text { for } 250 \mathrm{mg} / \mathrm{L} \text {. }\end{array}$ & $\begin{array}{l}\text { Pre-treatment with } 80 \% \\
\text { methanol extract resulted } \\
\text { rightward non-parallel } \\
\text { shift in } \mathrm{Ca}^{2+} \text { dose-response } \\
\text { curves by } \\
\text { 1) blocking } \mathrm{Ca}^{2+} \text { influx } \\
\text { via VDCC which relaxes } \\
\text { VSMC. }\end{array}$ & [48] \\
\hline $\begin{array}{l}\text { Camellia } \\
\text { sinensis O. Ktze } \\
\text { (Theaceae) }\end{array}$ & Black tea extract & $\begin{array}{l}\text { Male Sprague } \\
\text { Dawley rats }\end{array}$ & $\begin{array}{l}4(\mathrm{a}) \\
\text { theaflavin-3,3'-digallate } \\
\text { (TF3) } \\
\text { (Figure 4) }\end{array}$ & $\begin{array}{l}1.5 \mu \mathrm{g} / \mathrm{ml} \text { extract } \\
\text { and } 0.1,0.5 \mu \mathrm{g} / \mathrm{ml} \mathrm{TF} 3 \\
\text { significantly improved } \\
(\mathrm{p}<0.05) \\
\text { endothelium- } \\
\text { dependent } \\
\text { relaxations in } \\
\text { homocysteine- } \\
\text { treated rat aorta. }\end{array}$ & $\begin{array}{l}\text { Black tea extract exerts } \\
\text { effects by } \\
\text { 1) promoting Homocysteine } \\
\text { metabolism } \\
\text { 2) inhibition of } \\
\text { phosphorylated ATF3, eIF2 } \alpha \text {, } \\
\text { and cleaved ATF6 expression } \\
\text { which reduces endoplasmic } \\
\text { reticulum stress } \\
\text { 3) reducing oxidative stress }\end{array}$ & [49] \\
\hline
\end{tabular}




\section{Continued}

\begin{tabular}{|c|c|c|c|c|c|c|}
\hline $\begin{array}{l}\text { Cecropia } \\
\text { glaziovii Sneth } \\
\text { (Cecropiaceae) }\end{array}$ & $\begin{array}{l}\text { Leaves, } \\
\text { Aqueous extract } \\
\text { and n-butanol } \\
\text { fraction }\end{array}$ & $\begin{array}{l}\text { Rats and } \\
\text { mice of } \\
\text { three-month- } \\
\text { old }\end{array}$ & $\begin{array}{l}\text { 4(b) procyanidin B5 } \\
\text { 4(c) procyanidin B3 } \\
\text { 4(d) catechin } \\
\text { 4(e) procyanidin B2 } \\
\text { 4(f) epicatechin } \\
\text { 4(g) procyanidin C1 } \\
\text { 4(h) orientin } \\
\text { 4(i) isoorientin and } \\
\text { 4(j) isovitexin } \\
\text { (Figure 4) }\end{array}$ & $\begin{array}{l}\text { Pronounced } \\
\text { hypotension. } \\
0.5 \mathrm{~g} / \mathrm{kg} / \mathrm{bid} \text {. }\end{array}$ & Not reported & {$[50]$} \\
\hline $\begin{array}{l}\text { Cistus } \\
\text { ladaniferus } \\
\text { (Cistaceae) }\end{array}$ & $\begin{array}{l}\text { Aerial parts, } \\
\text { Aqueous extract }\end{array}$ & $\begin{array}{l}\text { Adult Wistar } \\
\text { rats }\end{array}$ & $\begin{array}{l}4(\mathrm{k}) \text { quercetin } \\
\text { (Figure } 4 \text { ) }\end{array}$ & $\begin{array}{l}\text { Antihypertensive } \\
\text { properties. } \\
\text { Aqueous extract of } 500 \\
\mathrm{mg} / \mathrm{kg} / \text { day. }\end{array}$ & $\begin{array}{l}\text { The antihypertensive } \\
\text { effects of } \\
C \text {. ladaniferus } \\
\text { are mostly } \\
\text { 1) due to an } \\
\text { endothelium-dependent } \\
\text { vasodilatory activity. }\end{array}$ & [51] \\
\hline $\begin{array}{l}\text { Clitoria } \\
\text { ternatea } \\
\text { (Fabaceae) }\end{array}$ & $\begin{array}{l}\text { Petals, } \\
\text { Aqueous extract, } \\
\text { crude lyophilized } \\
\text { extracts (CLE) }\end{array}$ & Not reported & Not reported & $\begin{array}{l}6.7 \mathrm{mg} / \mathrm{mL} \text { CLE } \\
\text { induced } 61 \% \text { ACE I } \\
\text { inhibitory activity. }\end{array}$ & $\begin{array}{l}\text { 1) Reference [52] found } \\
\text { flavonoid compounds like } \\
\text { quercetin, kaempferol, } \\
\text { quercetin-3-rutinoside, } \\
\text { and (-) epicatechin } \\
\text { presenting more than } \\
42 \% \text { ACE I inhibition. } \\
\text { Flavonoids' number and } \\
\text { position of -OH groups } \\
\text { in the rings, as well as } \\
\text { the existence of double } \\
\text { bonds, which form stable } \\
\text { chelating complexes with } \\
\text { zinc in active site of } \\
\text { ACE I [53]. }\end{array}$ & {$[54]$} \\
\hline $\begin{array}{l}\text { Cochlospermum } \\
\text { vitifolium } \\
\text { (Cochlospermaceae) }\end{array}$ & $\begin{array}{l}\text { Bark, } \\
\text { Methanolic } \\
\text { extract }\end{array}$ & $\begin{array}{l}\text { Wistar rats } \\
\text { and } \\
\text { Spontaneously } \\
\text { hypertensive } \\
\text { rats }\end{array}$ & $\begin{array}{l}\text { 4(1) naringenin (NG) } \\
\text { (Figure } 4)\end{array}$ & $\begin{array}{l}120 \mathrm{mg} / \mathrm{kg} \text { extract, } \\
50 \text { and } 160 \mathrm{mg} / \mathrm{kg} \\
\text { NG exerted acute } \\
\text { antihypertensive effects }\end{array}$ & $\begin{array}{l}\text { The NO-cGMP pathway } \\
\text { has been identified as the } \\
\text { most important signaling } \\
\text { mechanism of plant } \\
\text { extracts and Naringenin's } \\
\text { vasorelaxant activities. } \\
\text { Other mechanisms } \\
\text { involved also- } \\
\text { 1) synthesis of NO } \\
\text { 2) } \text { PGI }_{2} \text { production } \\
\text { 3) Activation of } \mathrm{K}^{+} \\
\text {channel on endothelial } \\
\text { dysfunction. }\end{array}$ & [55] \\
\hline $\begin{array}{l}\text { Cocos nucifera } \\
\text { Linn. } \\
\text { (Arecaceae) }\end{array}$ & $\begin{array}{l}\text { Endocarp. } \\
\text { Ethanolic } \\
\text { extract }\end{array}$ & $\begin{array}{l}\text { Male Wistar } \\
\text { rats }\end{array}$ & $\begin{array}{l}\text { 5(a) ferulic acid } \\
\text { 5(b) vanillic acid } \\
\text { (Figure 5) } \\
\text { 3(h) chlorogenic acid } \\
\text { (Figure } 3 \text { ) }\end{array}$ & $\begin{array}{l}\text { Vasorelaxant and } \\
\text { antihypertensive } \\
\text { effects. } \\
300 \mathrm{mg} / \mathrm{kg} \text {. }\end{array}$ & $\begin{array}{l}\text { The vasorelaxant and } \\
\text { antihypertensive effects } \\
\text { of } C \text {. nucifera ethanolic } \\
\text { extract is linked to } \\
\text { 1) activating NO/GC } \\
\text { pathway directly } \\
\text { 2) muscarinic receptors } \\
\text { stimulation } \\
\text { 3) cyclooxygenase pathway }\end{array}$ & {$[56]$} \\
\hline
\end{tabular}




\section{Continued}

\begin{tabular}{|c|c|c|c|c|c|c|}
\hline $\begin{array}{l}\text { Coreopsis } \\
\text { tinctoria } \\
\text { (Asteraceae) }\end{array}$ & $\begin{array}{l}\text { Dried and } \\
\text { powdered } \\
\text { flower buds, } \\
\text { Ethanol extract }\end{array}$ & $\begin{array}{l}\text { Spontaneously } \\
\text { hypertensive } \\
\text { rats (SHR), } \\
\text { Wistar-Kyoto } \\
\text { rats }\end{array}$ & $\begin{array}{l}\text { 4(k) quercetin } \\
\text { (Figure 4) } \\
\text { 5(c) quercetagetin-7- } \\
\text { O-glucoside } \\
\text { 5(d) flavanomarein } \\
\text { 5(e) marein } \\
\text { 5(f) luteolin } \\
\text { 5(g) coreopsis chalcones } \\
\text { (Figure 5) }\end{array}$ & $\begin{array}{l}\text { Antihypertensive } \\
\text { activity. } \\
100 \mathrm{mg} / \mathrm{kg} \text { ethanol } \\
\text { extract. }\end{array}$ & $\begin{array}{l}\text { Flavonoids from } \\
C \text {. tinctoria ethanolic } \\
\text { extracts produce } \\
\text { decent effect by } \\
\text { 1) downregulating } \\
\text { plasma Ang-II and ACE, } \\
\mathrm{AT}_{1} \mathrm{R} \text {, transforming } \\
\text { grown factor- } \beta \text { (TGF- } \beta \text { ) } \\
\text { expression in left } \\
\text { ventricle, but } \\
\text { upregulating ACE II }\end{array}$ & {$[57]$} \\
\hline $\begin{array}{l}\text { Cratoxylum } \\
\text { formosum } \\
\text { (Hypericaceae) }\end{array}$ & $\begin{array}{l}\text { Leaves, } \\
\text { Aqueous extract }\end{array}$ & $\begin{array}{l}\text { Sprague- } \\
\text { Dawley rats }\end{array}$ & $\begin{array}{l}5(\mathrm{~h}) \text { phenolic acid } \\
\text { (Figure } 5 \text { ) }\end{array}$ & $\begin{array}{l}\text { Aqueous extract of } \\
100,300, \text { and } \\
500 \mathrm{mg} / \mathrm{kg} \text { lowered } \\
\mathrm{SBP} \\
(158.2 \pm 1.5 \mathrm{mmHg} \text {, } \\
137.4 \pm 2.1 \mathrm{mmHg} \text {, } \\
\text { and } 139.3 \pm 2.5 \\
\mathrm{mmHg}) \\
\text { significantly } \\
\text { (p }<0.05, \mathrm{n}=8) \\
\text { in hypertensive rats } \\
\text { against control. }\end{array}$ & $\begin{array}{l}\text { C. formosum aqueous } \\
\text { extract exhibits } \\
\text { therapeutic effects by } \\
\text { 1) rising plasma NO levels, } \\
\text { and decreasing oxidative } \\
\text { stress } \\
\text { 2) reducing serum ACE, } \\
\text { plasma Ang-II and } \mathrm{AT}_{1} \mathrm{R} \\
\text { upregulating in l-NAME } \\
\text { induced hypertensive rats } \\
\text { 3) suppressing RAS }\end{array}$ & {$[58]$} \\
\hline $\begin{array}{l}\text { Croton } \\
\text { schiedeanus } \\
\text { Schlecht } \\
\text { (Euphorbiaceae) }\end{array}$ & $\begin{array}{l}\text { Leaves, } \\
\text { Aqueous extract }\end{array}$ & $\begin{array}{l}\text { Spontaneously } \\
\text { hypertensive } \\
\text { rats }\end{array}$ & $\begin{array}{l}\text { Not been } \\
\text { elucidated }\end{array}$ & $\begin{array}{l}\text { Antihypertensive, } \\
\text { bradycardic, and } \\
\text { vasorelaxant effects. } \\
\text { Aqueous extract of } \\
5-100 \mathrm{mg} / \mathrm{kg} \text {. }\end{array}$ & $\begin{array}{l}\text { C. schiedeanus Aqueous } \\
\text { extract exerts } \\
\text { antihypertensive, } \\
\text { bradycardic, vasorelaxant } \\
\text { effects by } \\
\text { 1) } \mathrm{Ca}^{2+} \text { influx blocking } \\
\text { through VDCC }\end{array}$ & [59] \\
\hline $\begin{array}{l}\text { Curcuma } \\
\text { domestica } \\
\text { (Zingiberaceae) }\end{array}$ & $\begin{array}{l}\text { Curcumin } \\
\text { nanoemulsion }\end{array}$ & Not reported & $\begin{array}{l}\text { 5(i) curcumin } \\
\text { (Figure 5) }\end{array}$ & $\begin{array}{l}\text { Antihyperlipidemic, } \\
71.166 \% \text { inhibition of } \\
\text { HMG-CoA reductase } \\
\text { (HMGCR) compared } \\
\text { to pravastatin after } \\
\text { correction, ACE } \\
\text { inhibitory activity of } \\
\text { curcumin } \\
\text { nanoemulsion } \\
\text { at } 2 \mathrm{mg} / \mathrm{mL} \text {. }\end{array}$ & $\begin{array}{l}\text { Curcumin inhibits } \\
\text { HMGCR production } \\
\text { which synthesizes } \\
\text { cholesterol in liver [60]. }\end{array}$ & {$[61]$} \\
\hline $\begin{array}{l}\text { Echinodorus } \\
\text { grandiflorus } \\
\text { (Cham. \& Schltdl.) } \\
\text { Micheli. } \\
\text { (Alismataceae) }\end{array}$ & $\begin{array}{l}\text { Leaves, } \\
\text { Ethanol soluble } \\
\text { fraction } \\
\text { (ESEG) }\end{array}$ & $\begin{array}{l}\text { Male } \\
\text { Wistar } \\
\text { rats }\end{array}$ & Not reported & $\begin{array}{l}\text { Diuretic activity like } \\
\text { hydrochlorothiazide } \\
\text { of ESEG } \\
\text { ( } 30 \text { - } 300 \mathrm{mg} / \mathrm{kg} \text {, p.o.), } \\
\text { sparing } \mathrm{HCO}_{3}^{-} \text {and } \\
\text { serum nitrite } \\
\text { increased. } \\
\text { Furthermore, } \\
\text { intraduodenal ESEG } \\
\text { administration } \\
\text { induces } \\
\text { antihypertension and } \\
\text { hypotension in } 2 \mathrm{~K} 1 \mathrm{C} \\
\text { rats significantly. }\end{array}$ & $\begin{array}{l}\text { The hypotensive and } \\
\text { antihypertensive action } \\
\text { of ethanol soluble fraction } \\
\text { of } E \text {. grandiflorus are } \\
\text { mediated by } \\
\text { 1) muscarinic and } \\
\text { bradykinin B2 receptor } \\
\text { activation, with directly } \\
\text { involving NO and } \\
\text { prostaglandin pathways. }\end{array}$ & {$[62]$} \\
\hline
\end{tabular}




\section{Continued}

\begin{tabular}{|c|c|c|c|c|c|c|}
\hline $\begin{array}{l}\text { Eruca sativa Mill., } \\
\text { (Brassicaceae) }\end{array}$ & $\begin{array}{l}\text { Aerial parts, } \\
\text { Crude extract of } \\
\text { E. sativa, } \\
\text { n-hexane, } \\
\text { chloroform, } \\
\text { ethyl acetate, and } \\
\text { aqueous extract. }\end{array}$ & $\begin{array}{l}\text { Balb }{ }^{\mathrm{C}} \text { mice } \\
\text { and Sprague- } \\
\text { Dawley rats }\end{array}$ & $\begin{array}{l}4(\mathrm{k}) \text { quercetin } \\
\text { (Figure } 4) \\
5(\mathrm{j}) \text { erucin } \\
\text { (Figure 5) }\end{array}$ & $\begin{array}{l}\text { Antihypertensive } \\
\text { activity, } \\
\text { vasodilatory and } \\
\text { partly cardiac effects at } \\
1,3,10,30 \text { and } 100 \\
\mathrm{mg} / \mathrm{kg}\end{array}$ & $\begin{array}{l}\text { E. sativa aqueous and crude } \\
\text { extract mediated } \\
\text { antihypertensive effect } \\
\text { through } \\
\text { 1) NO release linked by } \\
\text { muscarinic receptors } \\
\text { 2) } \mathrm{Ca}^{+2} \text { influx and release } \\
\text { inhibitory effect }\end{array}$ & [63] \\
\hline $\begin{array}{l}\text { Erythrina } \\
\text { senegalensis DC } \\
\text { (Fabaceae) }\end{array}$ & $\begin{array}{l}\text { Stem barks, } \\
\text { Aqueous extract }\end{array}$ & $\begin{array}{l}\text { Male albinos } \\
\text { Wistar rats, } \\
\text { Hypertensive } \\
\text { diabetic rats } \\
\text { (HDR) }\end{array}$ & $\begin{array}{l}\text { Alkaloids, flavonoids, } \\
\text { phenols in extract } \\
\text { whose antidiabetic and } \\
\text { antihypertensive activity } \\
\text { have been showed [64]. }\end{array}$ & $\begin{array}{l}\text { Antihypertensive, } \\
\text { cardiomodulator, } \\
\text { antioxidant, } \\
\text { hypolipidemic, and } \\
\text { hypoglycemic } \\
\text { properties. } \\
100 \text { and } 200 \mathrm{mg} / \mathrm{kg} \text { of } \\
\text { aqueous extract were } \\
\text { tested on two groups } \\
\text { of HDR, for } 28 \text { days. }\end{array}$ & $\begin{array}{l}\text { Aqueous extract of } \\
\text { E. senegalensis mainly act by } \\
\text { 1) activating AMP-activated } \\
\text { protein kinase, expressing } \\
\text { Glucose transporter } 4 \text { and } \\
\text { Glucose transporter } 1 \text {, and } \\
\text { inhibiting protein tyrosine } \\
\text { phosphatase 1B by are } \\
\text { involved in stimulating } \\
\text { basal and insulin responsive } \\
\text { glucose uptake [65]. }\end{array}$ & {$[66]$} \\
\hline $\begin{array}{l}\text { Eucommia ulmoides } \\
\text { Oliv } \\
\text { (Eucommiaceae) }\end{array}$ & $\begin{array}{l}\text { Barks, } \\
50 \% \text { ethanol } \\
\text { extract (Lignans) } \\
(\text { EuL) }\end{array}$ & $\begin{array}{l}\text { Male Sprague- } \\
\text { Dawley rats } \\
\text { and male } \\
\text { spontaneously } \\
\text { hypertensive } \\
\text { rats. }\end{array}$ & Not reported & $\begin{array}{l}\text { EuL of } 150 \text { and } 300 \\
\mathrm{mg} / \mathrm{kg} \text { bid lowered } \\
\text { SBP significantly } \\
(\mathrm{p}<0.05, \mathrm{n}=8) \\
\text { than control. }\end{array}$ & $\begin{array}{l}\text { 1) EuL increased plasma NO } \\
\text { in vivo. This effect is linked } \\
\text { with endothelium, that did } \\
\text { not follow the result of in } \\
\text { vitro. In vivo EuL } \\
\text { metabolizes into } \\
\text { compounds which } \\
\text { release NO from } \\
\text { endothelium. EuL } \\
\text { in vitro cannot do it. }\end{array}$ & 西 \\
\hline $\begin{array}{l}\text { Eugenia uniflora L. } \\
\text { (Myrtaceae) }\end{array}$ & $\begin{array}{l}\text { Leaves, } \\
\text { Aqueous Crude } \\
\text { Extracts }\end{array}$ & $\begin{array}{l}\text { Normotensive } \\
\text { male Wistar } \\
\text { rats }\end{array}$ & Not reported & $\begin{array}{l}\text { For hypotension, } \mathrm{ED}_{50} \\
\text { was found to be } 3 \mathrm{mg} \\
\text { dried leaves (d.1.)/kg. } \\
\text { For diuresis, } \\
120 \mathrm{mg} \text { d.1./kg extract } \\
\text { exhibited most } \\
\text { potently compared } \\
\text { to amiloride. }\end{array}$ & $\begin{array}{l}\text { 1) Hypotensive effect of } \\
\text { the leave extract of } \\
\text { E. uniflora is moderated } \\
\text { by direct } \\
\text { vasodilation } \\
\text { 2) Weak diuresis is related } \\
\text { to renal blood flow increase. }\end{array}$ & {$[68]$} \\
\hline $\begin{array}{l}\text { Euphorbia } \\
\text { cuneata Vahl. } \\
\text { (Euphorbiaceae) }\end{array}$ & $\begin{array}{l}\text { Aerial parts, } \\
\text { Alcoholic extract }\end{array}$ & $\begin{array}{l}\text { Normotensive } \\
\text { albino rats }\end{array}$ & $\begin{array}{l}\text { 4(l) naringenin } \\
\text { (Figure } 4) \\
5(\mathrm{k}) \text { isoaromadendrin } \\
5(\mathrm{l}) \text { taxifolin } \\
5(\mathrm{~m}) \text { isosinensin } \\
\text { (Figure 5) }\end{array}$ & $\begin{array}{l}\text { Naringenin ( } 3.3 \mathrm{mg} / \mathrm{kg}) \\
\text { decreased } \mathrm{BP} \text { by } \\
20 \mathrm{mmHg} \text {; } \\
\text { isoaromadendrin } \\
(3.3 \mathrm{mg} / \mathrm{kg} \text { ) decreased } \\
\mathrm{BP} \text { and heart rate }(\mathrm{HR}) \\
\text { by } 36.5 \mathrm{mmHg} \text { and } 4 \% \\
\text { respectfully; taxifolin } \\
(3.3 \mathrm{mg} / \mathrm{kg}) \text { decreased } \\
\mathrm{BP} \text { by } 20 \mathrm{mmHg} \text {; } \\
\text { isosinensin }(3.3 \mathrm{mg} / \mathrm{kg}) \\
\text { decreased } \mathrm{BP} \text { and } \\
\mathrm{HR} \text { by } 15 \mathrm{mmHg} \text { and } \\
6.2 \% \text { respectfully; } \\
\text { isosinensin }(6.6 \mathrm{mg} / \mathrm{kg}) \\
\text { decreased BP and } \mathrm{HR} \\
\text { by } 16.6 \mathrm{mmHg} \text { and } \\
16.6 \% \text { respectfully }\end{array}$ & $\begin{array}{l}\text { 1) Isosinensin found in } \\
\text { alcoholic extracts of } \\
E \text {. cuneata lowers blood } \\
\text { pressure due to decrease } \\
\text { in HR produced by } \\
\text { vasodilatation } \\
\text { 2) Isoaromadendrin was } \\
\text { most potent having four } \\
\text { hydroxyl groups. }\end{array}$ & [69] \\
\hline
\end{tabular}




\section{Continued}

\begin{tabular}{|c|c|c|c|c|c|c|}
\hline $\begin{array}{l}\text { Inula viscosa } \mathrm{L} . \\
\text { (Asteraceae) }\end{array}$ & $\begin{array}{l}\text { Leaves, } \\
\text { Petroleum ether } \\
\text { extract, } \\
\text { dichloromethane } \\
\text { extract, ethyl } \\
\text { acetate extract } \\
\text { and methanol } \\
\text { extract. }\end{array}$ & $\begin{array}{l}\text { Hypertensive } \\
\text { l-NAME } \\
\text { Wistar rats }\end{array}$ & $\begin{array}{l}\text { 5(n) } \\
\text { 3-O-methylquercetine } \\
\text { 5(o) cynarin } \\
\text { 5(f) luteolin } \\
\text { (Figure 5) } \\
\text { 3(h) chlorogenic acid } \\
\text { (Figure 3) }\end{array}$ & $\begin{array}{l}\text { Antihypertensive } \\
\text { effect. } \\
\text { Methanol extract of } 40 \\
\mathrm{mg} / \mathrm{kg} \text {. }\end{array}$ & $\begin{array}{l}\text { 1) Methanol extract } \\
\text { exhibited antihypertensive } \\
\text { effect predominantly by } \\
\text { endothelium-dependent } \\
\text { vasodilation. } \\
\text { 2) Chlorogenic acid and } \\
\text { cynarin isolated from } \\
\text { I. viscosa Methanol extract, } \\
\text { possess strong vasorelaxant } \\
\text { activity. }\end{array}$ & {$[70]$} \\
\hline $\begin{array}{l}\text { Ipomoea } \\
\text { hederacea Jacq. } \\
\text { (Convolvulaceae) }\end{array}$ & $\begin{array}{l}\text { Dried seeds, } \\
\text { Aqueous- } \\
\text { ethanolic } \\
\text { extracts, butanol } \\
\text { fraction (Ih.Bn) }\end{array}$ & Albino rats & Not specified & $\begin{array}{l}\text { Antihypertensive } \\
\text { activity. Ih.Bn of } \\
0.01-100 \mathrm{mg} / \mathrm{kg} \text { body } \\
\text { weight (BW) dose } \\
\text { dependently decreased } \\
\text { DBP, SBP, HR, mean } \\
\text { arterial pressure } \\
\text { (MAP), pulse pressure. }\end{array}$ & $\begin{array}{l}\text { 1) Potent hypotensive effect } \\
\text { was presented by butanol } \\
\text { fractions of } I \text {. hederacea by } \beta \\
\text { blocking, } \alpha_{1} \text { blocking, and } \\
\text { stimulating inducible NO } \\
\text { synthase/cyclic guanosine } \\
\text { monophosphate (cGMP). }\end{array}$ & 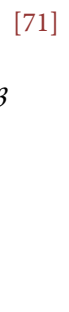 \\
\hline $\begin{array}{l}\text { Kalanchoe pinnata } \\
\text { (Crassulaceae) }\end{array}$ & $\begin{array}{l}\text { Leaves, } \\
\text { Aqueous extract }\end{array}$ & $\begin{array}{l}\text { Male albinos } \\
\text { Wistar rats }\end{array}$ & Not elucidated & $\begin{array}{l}\text { Antihypertensive } \\
\text { activity. } \\
\text { In salt hypertensive } \\
\text { rats, concurrent } \\
\text { administration of } \\
25,50 \text { and } 100 \\
\text { mg/kg/day extract } \\
\text { prevented SBP increase } \\
\text { significantly by } 32 \% \text {, } \\
24 \%, 47 \% \text { and also } \\
\text { reduced DBP increase } \\
\text { by } 35 \%, 33 \%, 56 \% \text {. }\end{array}$ & $\begin{array}{l}\text { Antihypertensive extracts } \\
\text { of } K \text {. pinnata act by } \\
\text { cardiode-pression, } \\
\text { increasing diuresis or } \\
\text { through vasorelaxant } \\
\text { activity. } \\
\text { 1) Conversion from } \mathrm{O}_{2}^{-} \text {to } \\
\mathrm{H}_{2} \mathrm{O} \text { and } \mathrm{H}_{2} \mathrm{O}_{2} \text { is catalyzed } \\
\text { by SOD, thus SOD } \\
\text { metabolizes } \mathrm{O}_{2}^{-} \text {and } \\
\text { prevents } \mathrm{HTN}^{[72]} \text {. }\end{array}$ & {$[73]$} \\
\hline $\begin{array}{l}\text { Laelia anceps } \\
\text { (Orchidaceae) }\end{array}$ & $\begin{array}{l}\text { Roots, } \\
\text { crude } \\
\text { methanolic } \\
\text { extract }\end{array}$ & Wistar rats & $\begin{array}{l}\text { 5(p) 2,7-dihydroxy- } \\
3,4,9- \\
\text { trimethoxyphenanthrene } \\
\text { (Figure 5) }\end{array}$ & $\begin{array}{l}\text { Vasorelaxant and } \\
\text { antihypertensive } \\
\text { effects. } \\
\text { L-type (voltage-gated) } \\
\mathrm{Ca}^{2+} \text { channel } \\
(\mathrm{L}-\mathrm{VGCC}) \text { agonist FPL } \\
64176 \text { ( } 3.16 \mu \mathrm{M}) \text { - } \\
\text { induced contraction } \\
\text { was significantly } \\
\text { diminished by } 11.2 \text {, } \\
65 \mu \mathrm{m} / \mathrm{mL} \text { methanolic } \\
\text { extract }\end{array}$ & $\begin{array}{l}\text { 1) Root extract of } L \text {. anceps } \\
\text { causes vasorelaxation by } \\
\text { blockade of L-VGCC. }\end{array}$ & {$[74]$} \\
\hline $\begin{array}{l}\text { Laelia autumnalis } \\
\text { (Orchidaceae) }\end{array}$ & $\begin{array}{l}\text { Plant material, } \\
\text { crude } \\
\text { methanolic } \\
\text { extract (MELa) }\end{array}$ & Wistar rats & Not reported & $\begin{array}{l}\text { Vasorelaxant and } \\
\text { antihypertensive } \\
\text { activity. } \\
\text { MELa } \\
(0.15-50 \mu \mathrm{g} / \mathrm{mL}) \text {, } \\
100 \mathrm{mg} / \mathrm{kg} \text { (orally). }\end{array}$ & $\begin{array}{l}\text { Methanolic extract of } \\
\text { L. autumnalis produced } \\
\text { antihypertensive effect by } \\
\text { 1) inhibiting VGCC, } \\
\text { receptor-controlled } \mathrm{Ca}^{2+} \\
\text { channel, cGMP pathway } \\
\text { involving blocking of } \mathrm{Ca}^{2+} \\
\text { channels through } \\
\text { endothelium-independent } \\
\text { pathway } \\
\text { 2) inhibiting Ca }{ }^{2+} \\
\text { mobilization from } \\
\text { intracellular stores } \\
\text { 3) increasing cGMP levels }\end{array}$ & {$[75]$} \\
\hline
\end{tabular}




\section{Continued}

\begin{tabular}{|c|c|c|c|c|c|c|}
\hline $\begin{array}{l}\text { Lepidium sativum } \mathrm{L} \\
\text { (Brassicaceae) }\end{array}$ & $\begin{array}{l}\text { Seeds, } \\
\text { Aqueous extract }\end{array}$ & $\begin{array}{l}\text { WKY and } \\
\text { spontaneously } \\
\text { hypertensive } \\
\text { male rats }\end{array}$ & Not determined & $\begin{array}{l}\text { Decreasing BP and } \\
\text { increasing water and } \\
\text { electrolytes excretion. } \\
20 \mathrm{mg} / \mathrm{kg} \text { for } 3 \text { weeks. }\end{array}$ & $\begin{array}{l}\text { L. Sativum aqueous extract } \\
\text { demonstrated } \\
\text { antihypertensive effects- } \\
\text { 1) by mediated diuretic and } \\
\text { natriuretic action. }\end{array}$ & [76] \\
\hline $\begin{array}{l}\text { Linum } \\
\text { usitatissimum } \\
\text { (Liliaceae) }\end{array}$ & Seed & $\begin{array}{l}\text { Sprague } \\
\text { Dawley } \\
\text { normotensive } \\
\text { male rats }\end{array}$ & $\begin{array}{l}\text { 5(q) secoisolariciresinol } \\
\text { diglucoside }(\mathrm{SDG}) \\
\text { (Figure 5) }\end{array}$ & $\begin{array}{l}\text { In vivo } \\
\text { antihypertensive } \\
\text { activity. } \\
\text { Decrease in SBP, DBP, } \\
\text { and MAP were dose } \\
\text { dependent for SDG of } \\
3,5 \mathrm{mg} / \mathrm{kg}, 5-150 \\
\text { mins after } \\
\text { administration. } \\
\text { Pretreatment with } \\
\text { methylene blue } \\
(1 \mathrm{mg} / \mathrm{kg}) \text { prevented } \\
\text { SDG (10 mg/kg) } \\
\text { induced reduction in } \\
\text { arterial pressures. }\end{array}$ & $\begin{array}{l}\text { SDG exhibited } \\
\text { antihypertensive effect by } \\
\text { 1) directly stimulating GC } \\
\text { (like nitrovasodilator) and } \\
\text { not due to NO synthase } \\
\text { 2) due to SDG's metabolites } \\
\text { (secoisolariciresinol, } \\
\text { enterolactone and } \\
\text { enterodiol) }\end{array}$ & [77] \\
\hline $\begin{array}{l}\text { Melothria } \\
\text { maderaspatana } \\
\text { (Cucurbitaceae) }\end{array}$ & $\begin{array}{l}\text { Leaf, } \\
\text { Ethyl acetate } \\
\text { extract }\end{array}$ & $\begin{array}{l}\text { Male albino } \\
\text { Wistar rats }\end{array}$ & $\begin{array}{l}\text { 5(a) ferulic acid } \\
\text { (Figure 5) }\end{array}$ & $\begin{array}{l}\text { In vivo } \\
\text { antihypertensive } \\
\text { activity. } \\
30,60,120 \mathrm{mg} / \mathrm{kg} \\
\text { BW extract reduced } \\
\text { SBP and DBP } \\
\text { significantly }(\mathrm{p}<0.05) \\
\text { after } 6 \text { weeks of } \\
\text { administration in } \\
\text { DOCA-salt } \\
\text { hypertensive rats } \\
\text { than control. }\end{array}$ & $\begin{array}{l}\text { Ferulic acid found in the } \\
\text { extract was reported } \\
\text { having antihypertensive } \\
\text { effect on spontaneously } \\
\text { hypertensive rats [78] by } \\
\text { 1) NO-mediated } \\
\text { vasodilation } \\
\text { 2) improving } \\
\text { bioavailability } \\
\text { of NO }\end{array}$ & [79] \\
\hline $\begin{array}{l}\text { Mesona } \\
\text { procumbens Hemsl. } \\
\text { (Lamiaceae) }\end{array}$ & $\begin{array}{l}\text { Dried full plant, } \\
\text { Water extract } \\
\text { (WEHT) }\end{array}$ & $\begin{array}{l}\text { Male } \\
\text { 6-week-old } \\
\text { spontaneously } \\
\text { hypertensive } \\
\text { rats and } \\
\text { Wistar-Kyoto } \\
\text { rats }\end{array}$ & $\begin{array}{l}5(\mathrm{r}) \text { caffeic acid }(\mathrm{CA}) \\
\text { (Figure 5) }\end{array}$ & $\begin{array}{l}\text { In vivo } \\
\text { antihypertensive } \\
\text { activity. } \\
\text { WEHT ( } 1 \mathrm{~g} / \mathrm{kg} \text { of } \mathrm{BW}) \\
\text { significantly reduced } \\
\text { SBP, DBP, HR by } \\
17.7 \%, 11 \% \text {, and } 7.3 \% \text {. } \\
\text { CA }(0.1 \mathrm{~g} / \mathrm{kg} \text { of BW }) \\
\text { significantly reduced } \\
\text { SBP, DBP, HR by } \\
23.4 \%, 15 \%, 11.2 \% \text {. }\end{array}$ & $\begin{array}{l}\text { 1) Water extract of } \\
M \text {. procumbens had } \\
\text { scavenging activity on free } \\
\text { radicals and ROS } \\
\text { (e.g., hydroxyl or } \\
\text { peroxyl/hydroperoxy } \\
\text { radicals) } \\
\text { 2) plasma metabolites of } \\
\text { CA act as antioxidants } \\
\text { 3) Both reduced oxidative } \\
\text { stresses, or increased } \\
\text { antioxidant capacity in cell. }\end{array}$ & [80] \\
\hline $\begin{array}{l}\text { Moringa oleifera } \\
\text { (Moringaceae) }\end{array}$ & $\begin{array}{l}\text { Leaves, } \\
\text { Hot water } \\
\text { extract }\end{array}$ & $\begin{array}{l}\text { Frog heart, } \\
\text { Taenia coli of } \\
\text { guinea pig }\end{array}$ & Not reported & $\begin{array}{l}\text { Alkaloidal salts } \\
\text { ( } 3 \text { - } 48 \mathrm{ng} / \mathrm{ml}) \text { collected } \\
\text { from the extract } \\
\text { showed negative } \\
\text { inotropic effect on } \\
\text { isolated frog heart } \\
\text { dose-dependently; } \\
\text { inhibited calcium } \\
\text { response on frog } \\
\text { heart and guinea pig } \\
\text { taenia coli. }\end{array}$ & $\begin{array}{l}\text { Alkaloidal salts from } \\
\text { M. oleifera hot water extract } \\
\text { induced } \\
\text { 1) negative inotropic effect } \\
\text { because of the presence of } \\
\mathrm{CCB} \text {, or } \mathrm{Ca}^{2+} \text { antagonist. }\end{array}$ & [81] \\
\hline
\end{tabular}




\section{Continued}

\begin{tabular}{|c|c|c|c|c|c|c|}
\hline $\begin{array}{l}\text { Mucuna pruriens } \mathrm{L} . \\
\text { (Fabaceae) }\end{array}$ & $\begin{array}{l}\text { Seeds, } \\
\text { Ethyl acetate } \\
\text { extract (MPEA) }\end{array}$ & Wistar rats & $\begin{array}{l}\text { 6(a) genistein } \\
\text { 6(b) ursolic acid (UA) } \\
\text { 6(c) L-3,4- } \\
\text { dihydroxyphenylalanine } \\
\text { (L-DOPA) } \\
\text { (Figure 6) }\end{array}$ & $\begin{array}{l}\text { In vitro } \\
\text { antihypertensive } \\
\text { activity. } \\
\text { IC50 of MPEA, } \\
\text { Genistein, UA, } \\
\text { L-DOPA are } \\
156.45 \pm 3.90 \mu \mathrm{g} / \mathrm{mL} \text {, } \\
68.59 \pm 2.47 \mu \mathrm{g} / \mathrm{mL} \text {, } \\
465.83 \pm 51.2 \mu \mathrm{g} / \mathrm{mL} \text {, } \\
\text { and } \\
119.58 \pm 4.53 \mu \mathrm{g} / \mathrm{mL} \\
(\mathrm{n}=3) .\end{array}$ & $\begin{array}{l}\text { Ethyl acetate extract of } \\
M \text {. pruriens, Genistein, } \\
\text { UA, L-DOPA showed } \\
\text { 1) inhibition by } \\
\text { non-competitive mode } \\
\text { 2) ACE inhibition by } \\
\text { protein precipitating } \\
\text { (L-DOPA showed very } \\
\text { little precipitation). }\end{array}$ & [82] \\
\hline $\begin{array}{l}\text { Nigella damascene } \\
\text { (Ranunculaceae) }\end{array}$ & $\begin{array}{l}\text { Flour of Seeds, } \\
\text { Methanol extract }\end{array}$ & Not reported & Not reported & $\begin{array}{l}\text { Highest } 43.24 \% \\
\text { ACE inhibition was } \\
\text { shown for bound } \\
\text { phenolic-acid } \\
\text { extract of seed flour. } \\
\text { Highest } 84.385 \% \\
\text { antioxidant activity } \\
\text { was shown for } \\
\text { glutelin-1 fraction } \\
\text { of free phenolic- } 25^{\circ} \mathrm{C} \\
\text { extract. }\end{array}$ & Not reported & [83] \\
\hline $\begin{array}{l}\text { Nigella arvensis } \\
\text { (Ranunculaceae) }\end{array}$ & $\begin{array}{l}\text { Flour of Seeds, } \\
\text { Methanol extract }\end{array}$ & $\begin{array}{l}\text { Not } \\
\text { reported }\end{array}$ & Not reported & $\begin{array}{l}\text { Highest } 55.55 \% \\
\text { ACE inhibition was } \\
\text { shown for free } \\
\text { phenolic- } 25^{\circ} \mathrm{C} \text { extract } \\
\text { of seed flour. } \\
\text { Highest } 69.76 \% \\
\text { antioxidant activity } \\
\text { was shown for } \\
\text { albumin fraction } \\
\text { of free phenolic- } 25^{\circ} \mathrm{C} \\
\text { extract. }\end{array}$ & Not reported & [83] \\
\hline $\begin{array}{l}\text { Ocimum } \\
\text { gratissimum } \\
\text { (Lamiaceae) }\end{array}$ & $\begin{array}{l}\text { Fresh whole } \\
\text { plant with } \\
\text { leaves, stems, } \\
\text { and } \\
\text { flowers, } \\
\text { Water extract }\end{array}$ & $\begin{array}{l}\text { Wistar } \\
\text { Kyoto rats, } \\
\text { spontaneously } \\
\text { hypertensive } \\
\text { rats }\end{array}$ & $\begin{array}{l}6(d) \text { rutin } \\
\text { (Figure 6) }\end{array}$ & $\begin{array}{l}\text { In vitro and in vivo } \\
\text { antihypertensive } \\
\text { activity. } \\
\text { IC }_{50} \text { of the water } \\
\text { extract, and Rutin } \\
\text { are } \\
56.3 \pm 3.12 \mu \mathrm{g} / \mathrm{mL} \text {, } \\
\text { and } \\
43.08 \mu \mathrm{g} / \mathrm{mL}(\mathrm{n}=3) \text {. }\end{array}$ & $\begin{array}{l}\text { Rutin found in water } \\
\text { extract of } O \text {. gratissimum } \\
\text { 1) inhibited ACE } \\
\text { 2) inhibited endothelin-1 } \\
\text { (ET-1) }\end{array}$ & [84] \\
\hline $\begin{array}{l}\text { Olea europea L. } \\
\text { variety Picual } \\
\text { (Oleaceae) }\end{array}$ & $\begin{array}{l}\text { Fruits, } \\
\text { Water-soluble } \\
\text { extract of } \\
\text { olive oil }\end{array}$ & $\begin{array}{l}\text { Male } \\
\text { Spontaneously } \\
\text { hypertensive } \\
\text { rats }\end{array}$ & Not reported & $\begin{array}{l}\text { In vitro and in vivo } \\
\text { antihypertensive } \\
\text { effect. } \\
\text { Peptides } \\
(0.425 \mathrm{mg} / \mathrm{kg} \text { of } \mathrm{BW}) \\
\text { in the extract reduced } \\
\text { maximum } 20 \mathrm{mmHg} \\
\text { BP at } 6 \mathrm{~h} \\
(\mathrm{IC} 50=2.5 \pm 0 \mu \mathrm{g} \\
\text { protein } / \mathrm{mL}, \mathrm{n}=3) \text {. }\end{array}$ & $\begin{array}{l}\text { Olive oil water-soluble } \\
\text { extract from } O \text {. europea } \\
\text { showed antihypertensive } \\
\text { effect by } \\
\text { 1) inhibiting ACE } \\
\text { 2) increasing NO } \\
\text { bioavailability } \\
\text { 3) acting on ET-1 } \\
\text { expression }\end{array}$ & [85] \\
\hline
\end{tabular}




\section{Continued}

\begin{tabular}{|c|c|c|c|c|c|c|}
\hline $\begin{array}{l}\text { Orthosiphon } \\
\text { aristatus } \\
\text { (Lamiaceae) }\end{array}$ & $\begin{array}{l}\text { Leaves, } \\
\text { Chloroform- } \\
\text { soluble portion } \\
\text { from the water } \\
\text { decoction of } \\
\text { the leaves }\end{array}$ & $\begin{array}{l}\text { Stroke prone } \\
\text { spontaneously } \\
\text { hypertensive } \\
\text { rats (SHRSP), } \\
\text { Male Wistar } \\
\text { rats, male } \\
\text { Hartley } \\
\text { guinea pigs }\end{array}$ & $\begin{array}{l}\text { 6(e) } \\
\text { methylripariochromene } \\
\text { A (MRC) } \\
6(\mathrm{f}) \\
\text { acetovanillochromene } \\
\text { (AVC) } \\
6(\mathrm{~g}) \text { orthochromene } \\
\text { A (OC) } \\
\text { (Figure 6) }\end{array}$ & $\begin{array}{l}100 \mathrm{mg} / \mathrm{kg} \mathrm{MRC} \\
\text { decreased } 15 \text { to } 30 \\
\text { mmHg mean BP of } \\
\text { SHRSP at } 3.5 \mathrm{~h} \text { to } 24 \mathrm{~h} \\
(\mathrm{p}<0.05 \text { or } \mathrm{p}<0.01, \\
\mathrm{n}=8) ; 3.8 \times 10^{-5} \mathrm{M} \\
\text { and } 1.1 \times 10^{-4} \mathrm{M} \mathrm{MRC} \\
\text { suppressed } \\
\text { contractile force of } \\
\text { isolated guinea pig } \\
\text { atria by } \\
18.8 \% \pm 2.6 \% \\
(\mathrm{p}<0.05, \mathrm{n}=4) \text { and } \\
54.74 \% \pm 2.8 \% \\
(\mathrm{p}<0.01, \mathrm{n}=4) . \\
\text { IC } 50 \text { of } \mathrm{AVC}, \mathrm{OC} \text { are } \\
1.01 \times 10^{-4} \mathrm{M}, \\
1.32 \times 10^{-4} \mathrm{M} .\end{array}$ & $\begin{array}{l}\text { Methylripariochromene } \\
\text { A isolated from the leaves } \\
\text { of } O \text {. aristatus } \\
\text { 1) decreased the slow } \mathrm{Ca}^{2+} \\
\text { inward current } \\
\text { 2) decreased CO } \\
\text { 3) increased urinary volume } \\
\text { and electrolyte excretions } \\
\text { 4) have } \mathrm{Ca}^{2+} \text { antagonism }\end{array}$ & {$[86]$} \\
\hline $\begin{array}{l}\text { Osyris abyssinica } \\
\text { var. speciosa } \\
\text { (Santalaceae) }\end{array}$ & $\begin{array}{l}\text { Aerial parts, } \\
\text { Alcoholic extract }\end{array}$ & $\begin{array}{l}\text { Normotensive } \\
\text { Wistar albino } \\
\text { rats }\end{array}$ & $\begin{array}{l}\text { 4(f) epicatechin } \\
\text { (Figure 4) }\end{array}$ & $\begin{array}{l}\text { Epicatechin of } 3.3 \\
\mathrm{mg} / \mathrm{kg} \text { decreased } \mathrm{BP} \text {, } \\
\text { and } \mathrm{HR} \text { by } 8.3 \mathrm{mmHg} \text {, } \\
\text { and } 6 \% \text { respectfully; } \\
\text { and } 6.6 \mathrm{mg} / \mathrm{kg} \\
\text { decreased } \mathrm{BP} \text {, and } \\
\mathrm{HR} \text { by } 8.3 \mathrm{mmHg} \text {, and } \\
7.1 \% \text { respectfully. }\end{array}$ & $\begin{array}{l}\text { Epicatechin found from } \\
\text { O. abyssinica } \\
\text { 1) Lower HR by } \\
\text { vasodilatation }\end{array}$ & [69] \\
\hline $\begin{array}{l}\text { Parkia speciosa } \\
\text { (Fabaceae) }\end{array}$ & $\begin{array}{l}\text { Seeds, } \\
\text { Hydrolyzed } \\
\text { with and } \\
\text { without Alcalase }\end{array}$ & Not reported & Not found & $\begin{array}{l}\text { Hydrolyzed samples } \\
\text { showed slightly more } \\
\text { DPPH scavenging } \\
\text { activity of } 2.1-2.9 \mathrm{mg} \\
\text { gallic acid equivalent } \\
\text { (GAE)/g seed than } \\
\text { non-hydrolyzed ones } \\
(1.6 \text { - } 2.2 \text { mg GAE/g } \\
\text { seed). } \\
\text { Hydrolyzed samples } \\
\text { inhibited } \\
50.6 \% \text { - } 80.2 \% \text { of } \\
\text { ACE activity. }\end{array}$ & $\begin{array}{l}\text { Hydrolyzed seeds of } \\
P . \text { speciosa } \\
\text { 1) Inhibit ACE }\end{array}$ & [87] \\
\hline $\begin{array}{l}\text { Passiflora edulis } \\
\text { (Passifloraceae) }\end{array}$ & $\begin{array}{l}\text { Fruit Peel, } \\
\text { Ethanol extract }\end{array}$ & $\begin{array}{l}\text { Male } \\
\text { Spontaneously } \\
\text { hypertensive } \\
\text { rats }\end{array}$ & $\begin{array}{l}\text { 6(h) edulilic acid (EA) } \\
6(\mathrm{i}) \text { anthocyanin } \\
\text { fraction (AF) } \\
\text { (Figure 6) }\end{array}$ & $\begin{array}{l}\text { For } 2.5 \text {, and } 50 \mathrm{mg} \\
\text { ethanol extract } / \mathrm{kg} \\
\mathrm{BW}, \text { maximum } \mathrm{MAP} \\
\text { reduced were } 8.9 \pm 3, \\
\text { and } 13 \pm 2.5 \mathrm{mmHg} \text {; } \\
\text { maximum SBP } \\
\text { reduced were } 10 \pm 2.9, \\
\text { and } 13.8 \pm 2.8 \mathrm{mmHg} \text {; } \\
\text { maximum } \mathrm{DBP} \\
\text { reduced were } 7.6 \pm 2.9 \text {, } \\
\text { and } 10.2 \pm 2.2 \mathrm{mmHg} \text {. } \\
\text { EA and AF } \\
\text { significantly decreased } \\
\text { (p<0.001) mean } \\
\text { variation in HR from } \\
\text { baseline over } 5 \text { days. }\end{array}$ & $\begin{array}{l}\text { Ethanol extract of } \\
P \text {. edulis peel extract } \\
\text { 1) diminishes sympathetic } \\
\text { nervous system activation }\end{array}$ & [88] \\
\hline
\end{tabular}


Md. M. A. Asif et al.

\section{Continued}

\begin{tabular}{|c|c|c|c|c|c|c|}
\hline $\begin{array}{l}\text { Petroselinum } \\
\text { crispum (Mill.) } \\
\text { Fuss. } \\
\text { (Apiaceae) }\end{array}$ & $\begin{array}{l}\text { Aerial parts, } \\
\text { Aqueous extract }\end{array}$ & $\begin{array}{l}\text { Albino adult } \\
\text { male Wistar } \\
\text { rats }\end{array}$ & Not reported & $\begin{array}{l}\text { In vivo and in vitro } \\
\text { antihypertensive effect. } \\
\text { Significant reduction } \\
\text { of SBP, MAP and DBP } \\
\text { ( }<<0.01 \text { ) was } \\
\text { observed after } 6 \mathrm{~h} \\
\text { of treating with } 160 \\
\mathrm{mg} / \mathrm{kg} \text { extract. } \\
\text { Significant } \\
\text { vasorelaxation } \\
(\mathrm{p}<0.0001) \text { of aortic } \\
\text { rings pre-contracted } \\
\text { by epinephrine was } \\
\text { seen for } \\
0.02-2.5 \mu \mathrm{g} / \mathrm{ml} \text { extract } \\
\left(\mathrm{IC} \mathrm{C}_{50}=0.38 \pm 0.07\right. \\
\mu \mathrm{g} / \mathrm{ml}) .\end{array}$ & $\begin{array}{l}\text { Aqueous extract of } \\
\text { P. crispum } \\
\text { 1) decreases tension in } \\
\text { endothelium-denuded } \\
\text { and endothelium-intact } \\
\text { aortic rings } \\
\text { 2) blocks the entry of } \\
\text { extracellular } \mathrm{Ca}^{2+} \text { via } \\
\text { blocking VOCC and ROCC. } \\
\text { 3) increases synthesis of NO. }\end{array}$ & [89] \\
\hline $\begin{array}{l}\text { Phaseolus vulgaris } \\
\text { L. varieties plus } \\
\text { black (PB), } \\
\text { azufrado higuera } \\
\text { (AH) and pinto } \\
\text { Saltillo (PS) } \\
\text { (Fabaceae) }\end{array}$ & $\begin{array}{l}\text { Seeds, } \\
\text { Protein } \\
\text { extraction by } \\
\text { isoelectric } \\
\text { precipitation }\end{array}$ & $\begin{array}{l}\text { Male Wistar } \\
\text { spontaneously } \\
\text { hypertensive } \\
\text { rats }\end{array}$ & Not reported & $\begin{array}{l}\text { Total hydrolysates } \\
\text { from each variety } \\
\text { showed ACE inhibition } \\
\text { of } \mathrm{IC}_{50}=4.34 \pm 0.29 \text {, } \\
4.82 \pm 1.59, \\
25.96 \pm 0.86 \mu \mathrm{g} / \mathrm{mL} \\
\text { respectively. } \\
\text { Peptide fraction }<1 \\
\mathrm{kDa} \text { showed highest } \% \\
\text { antioxidant activity } \\
\text { among each variety } \\
(99.2 \% \pm 0.9 \% \text {, } \\
87.6 \% \pm 0.7 \% \text {, and } \\
82.7 \% \pm 2.0 \% \\
\text { respectively). } \\
\text { Peptide fraction } \\
3-10 \mathrm{kDa} \text { of } \mathrm{AH} \\
\text { variety lowered SBP } \\
\text { up to } 27.13 \pm 11.17 \\
\text { mmHg at } 2 \mathrm{~h} \text { and up } \\
\text { to } 23.55 \pm 12.44 \mathrm{mmHg} \\
\text { at } 4 \mathrm{~h} \text { (p } \leq 0.01, \mathrm{n}=3) \text {. }\end{array}$ & Not reported & {$[90]$} \\
\hline $\begin{array}{l}\text { Phragmanthera } \\
\text { incana (Schum) } \\
\text { Balle } \\
\text { (Loranthaceae) }\end{array}$ & $\begin{array}{l}\text { Leaves, } \\
\text { Ethanol extract }\end{array}$ & $\begin{array}{l}\text { Wistar male } \\
\text { rats }\end{array}$ & Not found & $\begin{array}{l}50,100,200 \mathrm{mg} \\
\text { ethanol extract/kg } \\
\text { p.o. significantly } \\
\text { decreased }(\mathrm{p}<0.05 \\
\text { and } \mathrm{p}<0.001, \mathrm{n}=6 \text { ) } \\
\text { SBP compared to the } \\
\text { l-NAME rat group } \\
\text { after four weeks' } \\
\text { treatment. } \\
\text { 100, } 200 \mathrm{mg} \text { ethanol } \\
\text { extract/kg p.o. } \\
\text { significantly (p }<0.05 \text {, } \\
\mathrm{p}<0.01 \text { respectively, } \\
\mathrm{n}=6 \text { ) increased } \\
\text { serum nitrite levels } \\
\text { compared to the } \\
\text { 1-NAME rat group. }\end{array}$ & $\begin{array}{l}P \text {. incana ethanol extract } \\
\text { holds antihypertensive and } \\
\text { antioxidant activity by } \\
\text { 1) reducing peroxidation } \\
\text { of lipid } \\
\text { 2) restoring plasma nitrite } \\
\text { levels counterbalance the } \\
\text { effect of ROS }\end{array}$ & {$[91]$} \\
\hline
\end{tabular}




\section{Continued}

\begin{tabular}{|c|c|c|c|c|c|c|}
\hline $\begin{array}{l}\text { Picrasma } \\
\text { quassiodes } \\
\text { (D. Don) Benn. } \\
\text { (Simaroubaceae) }\end{array}$ & $\begin{array}{l}\text { Dried branches, } \\
\text { Dichloromethane } \\
\text { extract }\end{array}$ & $\begin{array}{l}\text { Male } \\
\text { spontaneously } \\
\text { hypertensive } \\
\text { rats (SHR), } \\
\text { Wistar Kyoto } \\
\text { rats }\end{array}$ & Not found & $\begin{array}{l}50,100, \text { and } 200 \mathrm{mg} \\
\text { extract/kg } \\
\text { significantly lowered } \\
(\mathrm{p}<0.01, \mathrm{n}=8) \mathrm{SBP} \\
\text { compared to control } \\
\text { group. } \\
100 \text {, and } 200 \mathrm{mg} \\
\text { extract/kg } \\
\text { significantly } \\
\text { increased NO and } \\
\text { SOD than SHR } \\
\text { control group } \\
\text { (p < 0.01, p < 0.05 } \\
\text { respectively, } \mathrm{n}=6) .\end{array}$ & $\begin{array}{l}\text { Extract of } P \text {. quassiodes } \\
\text { exerts effects by } \\
\text { 1) vascular oxidative stress } \\
\text { minimization by increasing } \\
\text { SOD activity } \\
\text { 2) endothelial function } \\
\text { preservation and increase } \\
\text { eNOS expression to } \\
\text { promote synthesis and } \\
\text { release of NO that result } \\
\text { in direct vasorelaxation. }\end{array}$ & [92] \\
\hline $\begin{array}{l}\text { Prunus serotina } \\
\text { Ehrh. } \\
\text { (Rosaceae) }\end{array}$ & $\begin{array}{l}\text { Fruits, } \\
\text { Lyophilized } \\
\text { aqueous and } \\
\text { methanolic } \\
\text { extracts }\end{array}$ & $\begin{array}{l}\text { Adult male } \\
\text { Wistar rats }\end{array}$ & $\begin{array}{l}\text { 3(h) chlorogenic acid } \\
\text { (CGA) } \\
\text { (Figure 3) } \\
7(\text { a) cyanidin-3-O- } \\
\text { rutinoside } \\
\text { 7(b) proanthocyanidins } \\
\text { 7(c) quercetine glycosides } \\
\text { (Figure 7) }\end{array}$ & $\begin{array}{l}\text { The flesh extract } \\
\text { showed } E_{\max } \text { of } \\
27.9 \% \pm 3.6 \%, \mathrm{EC}_{50} \\
\text { of } 120 \pm 5.7 \mu \mathrm{g} / \mathrm{mL} \text {, } \\
\text { peel extract showed } \\
\mathrm{E}_{\max } \text { of } 54.5 \% \pm 4 \% \text {, } \\
\mathrm{EC}_{50} \text { of } 34.9 \pm 3.4 \\
\mu \mathrm{g} / \mathrm{mL}, \text { and whole } \\
\text { fruit extract showed } \\
\mathrm{E}_{\max } \text { of } 59 \% \pm 5.9 \% \text {, } \\
\mathrm{EC} \mathrm{C}_{50} \text { of } 101.8 \pm 7.5 \\
\mu \mathrm{g} / \mathrm{mL} \text { vasorelaxant } \\
\text { response. }\end{array}$ & $\begin{array}{l}\text { 1) synergistic effect of the } \\
\text { compounds } \\
\text { 2) CGA inhibit ROS } \\
\text { generating enzymes } \\
\text { (NADPH, xanthine oxidase), } \\
\text { reduce the formation of } \\
\text { ONOO- and increase }^{-} \\
\text {bioavailability of NO. } \\
\text { It also has protective role } \\
\text { in eNOS [94]. }\end{array}$ & [95] \\
\hline $\begin{array}{l}\text { Psidium guineense } \\
\text { Sw. } \\
\text { (Myrtaceae) }\end{array}$ & $\begin{array}{l}\text { Leaves, } \\
\text { Essential oil }\end{array}$ & $\begin{array}{l}\text { Female and } \\
\text { male Swiss } \\
\text { mice, female } \\
\text { Wistar rats }\end{array}$ & $\begin{array}{l}7(\mathrm{~d}) \text { spathulenol } \\
\text { (Figure } 7 \text { ) }\end{array}$ & $\begin{array}{l}\text { Antioxidant activity. } \\
P \text {. guineense essential } \\
\text { oil and spathulenol } \\
\text { exhibited DPPH free } \\
\text { radical activity of } \\
\mathrm{IC}_{50}=60.7 \text { - } 65.92 \\
\text { and } \\
82.43-89.38 \mu \mathrm{g} / \mathrm{mL} \\
(\mathrm{n}=3) \text {, respectively; } \\
\text { and } \mathrm{MDA} \\
\text { lipoperoxidation with } \\
\mathrm{IC}=35.23-40.50 \\
\text { and } 24.30-28.68 \\
\mu \mathrm{g} / \mathrm{mL} \text { ( } \mathrm{n}=3 \text { ), } \\
\text { respectively. }\end{array}$ & Not reported & [96] \\
\hline
\end{tabular}




\section{Continued}

\begin{tabular}{|c|c|c|c|c|c|c|}
\hline $\begin{array}{l}\text { Salvia elegans Vahl. } \\
\text { (Lamiaceae) }\end{array}$ & $\begin{array}{l}\text { Aerial parts } \\
\text { (flowers, leaves, } \\
\text { and stems), } \\
\text { hydroalcoholic } \\
\text { extract (SeHA) } \\
\text { and n-butanol } \\
\text { extract } \\
\text { (SeBuOH) }\end{array}$ & $\begin{array}{l}\text { ICR albino } \\
\text { mice }\end{array}$ & Not found & $\begin{array}{l}\text { In vitro inhibitory } \\
\text { effect on ACE. } \\
\text { SeHA significantly } \\
\text { lowered }(\mathrm{p}<0.05) \\
\text { SBP from dose as } \\
\text { low as } 0.75 \mu \mathrm{g} / \mathrm{kg} \text {, } \\
\text { DBP at } 10 \mathrm{mg} / \mathrm{kg} \text {. } \\
\text { SeHA inhibited } \\
50.27 \% \pm 5.09 \% \\
\text { ACE } \\
(\mathrm{n}=5) \text { while } \\
\text { SeBuOH } \\
\text { inhibited } \\
78.40 \% \pm 2.24 \% \\
\text { ACE }(\mathrm{n}=5) .\end{array}$ & $\begin{array}{l}\text { SeHA inhibited } \\
\text { antihypertensive effect by } \\
\text { 1) inhibiting the secretion } \\
\text { of ET-1 } \\
\text { 2) increasing NO } \\
\text { production and release } \\
\text { 3) activating } \\
\mathrm{Ca}^{2+} \text {-dependent } \mathrm{K}^{+} \\
\text {conductance that allows } \\
\text { hyperpolarization after } \\
\text { entry of } \mathrm{Ca}^{2+} \text {. }\end{array}$ & [97] \\
\hline $\begin{array}{l}\text { Salvia verbenaca L. } \\
\text { (Lamiaceae) }\end{array}$ & $\begin{array}{l}\text { Aerial parts, } \\
\text { Alcoholic extract }\end{array}$ & $\begin{array}{l}\text { Normotensive } \\
\text { albino rats }\end{array}$ & $\begin{array}{l}\text { 7(e) 5-hydroxy-3, 4', } \\
\text { 7-trimethoxyflavone } \\
\text { (HMF), } \\
\text { 7(f) verbenacoside (VBC) } \\
\text { (Figure 7) }\end{array}$ & $\begin{array}{l}\mathrm{HMF}(3.3 \mathrm{mg} / \mathrm{kg}) \\
\text { decreased BP and HR } \\
\text { by } 30 \mathrm{mmHg} \text { and } \\
28.5 \% \text { respectfully; } \\
\text { VBC }(3.3 \mathrm{mg} / \mathrm{kg}) \\
\text { decreased } \mathrm{BP} \text { and } \\
\text { HR by } 13.2 \mathrm{mmHg} \\
\text { and } 15.4 \% \\
\text { respectfully; } \\
\text { Alcoholic extract } \\
0.5 \text { gm/kg decreased } \\
\text { BP and } \mathrm{HR} \text { by } \\
36.2 \mathrm{mmHg} \text { and } \\
18.18 \% \text {. }\end{array}$ & $\begin{array}{l}\text { 1) } 5 \text {-hydroxy- } 3,4 \text { ', } \\
\text { 7-trimethoxyflavone and } \\
\text { verbenacoside isolated } \\
\text { from alcoholic extract of } \\
\text { S. verbenaca decreased } \\
\text { HR by vasodilatation } \\
\text { 2) } 5 \text {-hydroxy- } 3,4 \text { ', } \\
\text { 7-trimethoxyflavone } \\
\text { showed potent activity } \\
\text { having four -OH groups } \\
\text { 3) alcoholic extract lowered } \\
\text { BP by synergistic effect of } \\
\text { flavonoids present }\end{array}$ & [69] \\
\hline $\begin{array}{l}\text { Sapium sebiferum } \\
\text { (L.) Roxb. } \\
\text { (Euphorbiaceae) }\end{array}$ & $\begin{array}{l}\text { Leaves, } \\
\text { Aqueous extract }\end{array}$ & $\begin{array}{l}\text { Spontaneously } \\
\text { hypertensive } \\
\text { rats }\end{array}$ & $\begin{array}{l}7(\mathrm{~g}) \\
\text { 6-O-galloyl-D-glucose } \\
\text { (GDG) } \\
\text { (Figure 7) }\end{array}$ & $\begin{array}{l}\text { GDG of } 1 \text {, and } \\
5 \mathrm{mg} / \mathrm{kg} \text { lowered } \\
\text { MAP by } \\
17.3 \pm 7.1 \text { and } \\
29.6 \pm 10.4 \mathrm{mmHg} \\
(\mathrm{n}=6) \text { in SHR, and } \\
\text { decrease in plasma } \\
\text { noradrenaline was } \\
\text { parallel to the } \\
\text { antihypertensive } \\
\text { action. }\end{array}$ & $\begin{array}{l}\text { GDG lowers blood } \\
\text { pressure by } \\
\text { 1) blocking of noradrenaline } \\
\text { release and/or } \\
\text { 2) direct vasorelaxation }\end{array}$ & [98] \\
\hline $\begin{array}{l}\text { Sechium edule } \\
\text { (Jacq.) Sw. } \\
\text { (Cucurbitaceae) }\end{array}$ & $\begin{array}{l}\text { Roots, } \\
\text { Hydroalcoholic } \\
\text { extract } \\
\text { (SeRHA) }\end{array}$ & $\begin{array}{l}\text { Male } \\
\text { Sprague- } \\
\text { Dawley albino } \\
\text { rats, } \\
\text { male ICR } \\
\text { albino mice }\end{array}$ & $\begin{array}{l}\text { 7(h) cinnamic acid } \\
\text { (Figure } 7 \text { ) }\end{array}$ & $\begin{array}{l}\text { SeRHA of } 200 \mathrm{mg} / \mathrm{kg} \\
\text { decreases DBP, } \\
\text { SBP significantly } \\
\text { after Ang-II } \\
\text { treatment } \\
(\mathrm{p}<0.05) . \\
\text { SeRHA of } \\
150,300,600 \mu \mathrm{g} / \mathrm{ml} \\
\text { lowered aorta } \\
\text { contraction by } \\
14 \%, 44 \% \text {, and } 66 \% \\
\text { of } \mathrm{E}_{\max } \text { after Ang-II } \\
\text { treatment (average } \\
\left.\mathrm{EC}_{50}=1.5 \times 10^{-8} \mathrm{M}\right) .\end{array}$ & $\begin{array}{l}\text { The hydroalcoholic root } \\
\text { extracts of } S \text {. edule may } \\
\text { 1) antagonize } \mathrm{AT}_{1} \mathrm{R} \text { or by } \\
\text { interfering } \mathrm{Ca}^{2+} \text { fluxes } \\
\text { activated by Ang-II } \\
\text { 2) obstruct the second } \\
\text { messenger system initiated } \\
\text { by Ang-II } \\
\text { 3) alter } \mathrm{Ca}^{2+} \text { fluxes in the } \\
\text { VSMC and on the RAAS. }\end{array}$ & [99] \\
\hline
\end{tabular}




\section{Continued}

\begin{tabular}{|c|c|c|c|c|c|c|}
\hline $\begin{array}{l}\text { Solanum } \\
\text { capsicoides All. } \\
\text { (Solanaceae) }\end{array}$ & $\begin{array}{l}\text { Aerial parts, } \\
\text { Methanol } \\
\text { extract }\end{array}$ & $\begin{array}{l}\text { Normotensive } \\
\text { Wistar-Kyoto } \\
\text { (WKY) rats, } \\
\text { Spontaneously } \\
\text { hypertensive } \\
\text { rats (SHR) }\end{array}$ & Not reported & $\begin{array}{l}\text { In vitro, in vivo } \\
\text { antihypertensive } \\
\text { activity. } \\
\text { Significant increase in } \\
\text { the vasorelaxation of } \\
\text { endothelium denuded } \\
\text { mesenteric rings from } \\
\text { SHR }\left(\mathrm{E}_{\max }=102.1 \% \pm\right. \\
5.7 \%, \text { EC } 50=29.6-55.8 \\
\mu \mathrm{g} / \mathrm{ml}, \mathrm{p}<0.05) \\
40 \mathrm{mg} / \mathrm{kg} \text { methanol } \\
\text { extract significantly } \\
(\mathrm{p}<0.05) \text { reduced } \\
\text { MAP greater in SHR } \\
(25.4 \% \pm 1.4 \%) \text { when } \\
\text { compared WKY rats } \\
(17.7 \% \pm 2.6 \%) \text {. }\end{array}$ & $\begin{array}{l}\text { Methanol extract induced } \\
\text { antihypertensive effect by } \\
\text { 1) reducing peripheral } \\
\text { vascular resistance } \\
\text { 2) reducing sensitivity } \\
\text { to the adrenergic agonist } \\
\text { 3) increasing NO sensitivity }\end{array}$ & {$[100]$} \\
\hline $\begin{array}{l}\text { Solanum melongena } \\
\text { (Solanaceae) }\end{array}$ & $\begin{array}{l}\text { Fruits, } \\
\text { Lyophilized } \\
\text { powders }\end{array}$ & $\begin{array}{l}\text { Male } \\
\text { 14-week-old } \\
\text { spontaneously } \\
\text { hypertensive } \\
\text { rats }\end{array}$ & $\begin{array}{l}\text { 7(i) acetylcholine } \\
\text { (ACh) } \\
\text { (Figure 7) }\end{array}$ & $\begin{array}{l}10^{-3}-10^{-0.5} \mu \mathrm{M} \text { ACh } \\
\text { which is identified } \\
\text { from eggplant powder, } \\
\text { exerted concentration- } \\
\text { dependent } \\
\text { vasorelaxation } \\
\left(\mathrm{EC}_{50}=0.0372 \pm 0.008\right. \\
\mu \mathrm{M}) . \\
\text { And SBP decreased } \\
\text { significantly }(\mathrm{p}<0.05) \\
\text { after } 3 \mathrm{~h} \text { and } 9 \mathrm{~h} \mathrm{by} \\
4.81 \text { and } 10 \mathrm{mmHg} \text {. }\end{array}$ & $\begin{array}{l}\text { ACh showed } \\
\text { antihypertensive activity by } \\
\text { 1) activating the M3 } \\
\text { muscarinic ACh receptor } \\
\text { on blood vessels } \\
\text { 2) suppressing the secretion } \\
\text { of hypertensive } \\
\text { catecholamines } \\
\text { 3) suppressing sympathetic } \\
\text { nervous activity }\end{array}$ & {$[101]$} \\
\hline $\begin{array}{l}\text { Tagetes Iucida Cav. } \\
\text { (Asteraceae) }\end{array}$ & $\begin{array}{l}\text { Aerial parts, } \\
\text { Ethanolic extract }\end{array}$ & $\begin{array}{l}\text { Normotensive } \\
\text { male Wistar } \\
\text { rats, male } \\
\text { spontaneously } \\
\text { hypertensive } \\
\text { rats }\end{array}$ & $\begin{array}{l}7(\mathrm{k}) 6,7,8- \\
\text { trimethoxycoumarin, } \\
7(1) \\
6,7 \text {-dimethoxycoumarin } \\
\text { (Figure } 7 \text { ) }\end{array}$ & $\begin{array}{l}\text { Ethanolic extract of } \\
3.03-1000 \mu \mathrm{g} / \mathrm{ml} \\
\text { showed } \mathrm{E}_{\max } \text { of } 99 \% \text {, } \\
\mathrm{EC}_{50} \text { of } 40.5 \mu \mathrm{g} / \mathrm{ml} \\
\text { (endothelium intact) } \\
\text { and } \mathrm{E}_{\max } \text { of } 100 \% \text {, } \\
\mathrm{EC}_{50} \text { of } 148.2 \mu \mathrm{g} / \mathrm{ml} \\
\text { (endothelium } \\
\text { denuded). The extract } \\
\text { relaxed KCl-induced } \\
\text { contraction with EC } 50 \\
\text { of } 100 \mu \mathrm{g} / \mathrm{ml} \text { and } \mathrm{E}_{\max } \\
\text { of } 100 \% \text {. Both } \\
\text { compounds displayed } \\
\text { significant activity (p < } \\
\text { 0.05) in concentration } \\
\text { and partly endothelium } \\
\text { dependent manner. }\end{array}$ & $\begin{array}{l}\text { Ethanol extract showed } \\
\text { endothelium derived } \\
\text { relaxant effect by } \\
\text { 1) Producing NO that } \\
\text { outspreads to VSMC to } \\
\text { activate sGC which produces } \\
\text { cGMP, and induces relaxes } \\
\text { smooth muscle as the main } \\
\text { second messenger. } \\
\text { 2) Blocking the L-VGCC }\end{array}$ & [104] \\
\hline
\end{tabular}




\section{Continued}

\begin{tabular}{|c|c|c|c|c|c|c|}
\hline $\begin{array}{l}\text { Terminalia } \\
\text { bellerica } \text { Roxb. } \\
\text { (Combretaceae) }\end{array}$ & $\begin{array}{l}\text { Fruits, } \\
\text { Aqueous- } \\
\text { methanolic } \\
\text { extract, } \\
\text { crude extract } \\
\text { (Tb.Cr) }\end{array}$ & $\begin{array}{l}\text { Sprague- } \\
\text { Dawley rats, } \\
\text { guinea-pigs, } \\
\text { rabbits }\end{array}$ & Not reported & $\begin{array}{l}\text { Tb.Cr of 100, 30, and } \\
10 \mathrm{mg} / \mathrm{kg} \text { showed a } \\
\text { dose-dependent } \\
\text { decrease of } \\
44.7 \% \pm 3.1 \% \text {, } \\
25.1 \% \pm 2.3 \% \text {, and } \\
15.6 \% \pm 2.0 \% \text { in } \mathrm{MAP} \\
\text { of rats; } 0.1-10 \mathrm{mg} / \mathrm{ml} \\
\text { inhibited guinea-pig } \\
\text { atrial force and } \\
\text { contraction rate } \\
\text { (EC } 50=4.5 \pm 1.2 \text { and } \\
5.9 \pm 1.3 \mathrm{mg} / \mathrm{mL} \\
\text { respectively, } \mathrm{n}=4) \\
\text { and } \\
\text { also relaxed } \mathrm{K}^{+} \text {and } \\
\text { phenylephrine }(\mathrm{PE}) \\
\text { induced contraction } \\
\text { in isolated rabbit aorta } \\
\text { (EC } 50=6.4 \pm 1.3 \text {, } \\
7.5 \pm 1.3 \mathrm{mg} / \mathrm{mL} \\
\text { respectively, } \mathrm{n}=4-5) \text {. }\end{array}$ & $\begin{array}{l}\text { Crude extract of } \\
T \text {. bellerica fruit induced } \\
\text { antihypertension by } \\
\text { 1) negative inotropic and } \\
\text { chronotropic effect due to } \\
\text { the } \mathrm{Ca}^{2+} \text { antagonism effect } \\
\text { decreasing CO and so } \\
\text { reducing BP } \\
\text { 2) equipotently blocking } \\
\mathrm{Ca}^{2+} \text { influx through } \\
\text { VDCC and ROCC } \\
\text { 3) suppressing the PE } \\
\text { agonist, and thus inhibiting } \\
\text { internal store release of } \mathrm{Ca}^{2+} \\
\text { 4) endothelium-independent } \\
\text { vasodilation }\end{array}$ & [105] \\
\hline $\begin{array}{l}\text { Thymus serpyllum } \\
\text { L. } \\
\text { (Lamiaceae) }\end{array}$ & $\begin{array}{l}\text { Whole plant, } \\
\text { Aqueous and } \\
\text { freeze-dried } \\
\text { extract }\end{array}$ & $\begin{array}{l}\text { Normotensive } \\
\text { Wistar rats, } \\
\text { Male } \\
\text { spontaneously } \\
\text { hypertensive } \\
\text { rats (SHR) }\end{array}$ & $\begin{array}{l}7(\mathrm{~m}) \text { rosmarinic acid } \\
\text { (Figure } 7 \text { ) }\end{array}$ & $\begin{array}{l}\text { Freeze dried extract } \\
(100 \mathrm{mg} / \mathrm{kg} \mathrm{BW} \\
\text { dissolved into } \\
\text { saline of } 0.2 \mathrm{ml}) \\
\text { decreased SBP, } \\
\text { DBP, and total } \\
\text { peripheral vascular } \\
\text { resistance significantly } \\
\text { (p }<0.001, \mathrm{n}=7) \text { in } \\
\text { SHR. } \\
\text { In vitro } \\
\text { NO-scavenging ability } \\
\text { of } 1 \mathrm{mg} / \mathrm{ml} \text { extract led } \\
\text { to } 63.43 \% \text { reduced } \\
\text { nitrite production } \\
\left(\mathrm{IC} \mathrm{C}_{50}=122.36 \mu \mathrm{m} / \mathrm{ml}\right) .\end{array}$ & $\begin{array}{l}\text { Rosmarinic acid found in } \\
\text { this extract had in vitro } \\
\text { antioxidant effect against } \\
\text { low density lipoprotein } \\
\text { (LDL) oxidation [106] by } \\
\text { 1) inhibiting conjugated } \\
\text { diene and TBARS formation. }\end{array}$ & [107] \\
\hline $\begin{array}{l}\text { Tropaeolum majus } \\
\text { L. } \\
\text { (Tropaeolaceae) }\end{array}$ & $\begin{array}{l}\text { Leaves, } \\
\text { semi-purified } \\
\text { fraction (TMLR) } \\
\text { and } \\
\text { hydroethanolic } \\
\text { extract (HETM) }\end{array}$ & $\begin{array}{l}\text { Wistar-Kyoto } \\
\text { rats, } \\
\text { Spontaneously } \\
\text { hypertensive } \\
\text { rats }\end{array}$ & $\begin{array}{l}7(\mathrm{n}) \text { isoquercitrin (ISQ) } \\
\text { (Figure 7) }\end{array}$ & $\begin{array}{l}50,100 \mathrm{mg} / \mathrm{kg} \text { TMLR, } \\
100,300 \mathrm{mg} / \mathrm{kg} \\
\text { HETM, and } \\
2,4 \mathrm{mg} / \mathrm{kg} \\
\text { ISQ significantly } \\
\text { ( } \mathrm{p}<0.001, \mathrm{n}=6) \\
\text { decreased MAP in a } \\
\text { dose-dependent } \\
\text { manner in } \\
\text { normotensive rats; } \\
300 \text { mg/kg HETM, } \\
50,100 \text { mg/kg TMLR } \\
\text { (p < } 0.01 \text { ) and } 10 \\
\text { mg/kg ISQ (p < } 0.001 \text { ) } \\
\text { significantly inhibited } \\
\text { ACE activity in } \\
\text { conscious rats } \\
\text { compared to control. }\end{array}$ & $\begin{array}{l}\text { Isoquercitrin inhibited } \\
\text { ACE activity but single } \\
\text { administration of } \\
\text { hydroethanolic extract, } \\
\text { semi-purified fraction, } \\
\text { Isoquercitrin did not } \\
\text { change HR because results } \\
\text { of ACE inhibition take } \\
\text { several months to } \\
\text { bring to light. } \\
\text { ACE inhibition by } \\
\text { Isoquercitrin may also } \\
\text { be occurring in central } \\
\text { nervous system. }\end{array}$ & [108] \\
\hline
\end{tabular}




\section{Continued}

\begin{tabular}{|c|c|c|c|c|c|c|}
\hline $\begin{array}{l}\text { Vitex pubescens } \\
\text { (Lamiaceae) }\end{array}$ & $\begin{array}{l}\text { Leaves, } \\
\text { Petroleum ether } \\
\text { extract (VPPE) }\end{array}$ & $\begin{array}{l}\text { Spontaneously } \\
\text { hypertensive } \\
\text { rats }\end{array}$ & $\begin{array}{l}\text { 7(d) Spathulenol } \\
\text { (Figure 7) }\end{array}$ & $\begin{array}{l}\text { VPPE of } 500 \mathrm{mg} / \mathrm{kg} \\
\text { significantly } \\
\text { decreased } \\
(\mathrm{p}<0.001, \mathrm{n}=6) \mathrm{SBP} \text {, } \\
\mathrm{DBP} \text { from } 3 \text { days, and } \\
0.25-4 \mathrm{mg} / \mathrm{ml} \\
\text { significantly relaxed } \\
(\mathrm{p}<0.001, \mathrm{n}=6) \\
\text { pre-contracted } \\
\text { endothelium intact } \\
\text { aortic ring. } \\
\text { Fraction } \mathrm{F} 2 \text {-VPPE of } \\
0.5,1,2 \mathrm{mg} / \mathrm{mL} \\
\text { significantly } \\
(\mathrm{p}<0.001) \text { attenuated } \\
\text { CaCl } 2 \text {-induced of } \\
\text { endothelium-denuded } \\
\text { aortic ring } \\
\text { vasoconstriction. }\end{array}$ & $\begin{array}{l}\text { Fraction F2-VPPE of } \\
V \cdot \text { pubescens induced } \\
\text { relaxation by } \\
\text { 1) Activating } \mathrm{K}_{\mathrm{ATP}} \text { channel } \\
\text { which causes } \\
\text { hyperpolarization and } \\
\mathrm{Ca}^{2+} \text { inflow inhibition } \\
\text { through VDCC } \\
\text { 2) intracellular } \mathrm{Ca}^{2+} \text { release } \\
\text { inhibition from } \mathrm{Ca}^{2+} \text { storage } \\
\text { 3) extracellular } \mathrm{Ca}^{2+} \text { inflow } \\
\text { inhibition through ROCC. } \\
\text { Spathulenol show } \\
\text { vasorelaxant activity [109] } \\
\text { by Ca }{ }^{2+} \text { inflow inhibition } \\
\text { through VDCC. }\end{array}$ & [110] \\
\hline
\end{tabular}

4) Elevates the transcription of the LXR $\alpha$ gene, which controls the CYP7A1 enzyme (encoding cholesterol-7a-hydroxlylase, an enzyme that participates in converting cholesterol to bile acids before excretion).

5) Prevents atherosclerotic lesion formation in the atherogenic diet-fed mice, as evidenced by a decrease in the atherogenic indicator and an increase in the \% ratio of HDL and total cholesterol [60].

In comparison to pure curcumin, curcumin nanoemulsion demonstrated a higher rate of ACE inhibition, which suggests that higher inhibition activity of curcumin exerted by the nanoemulsion carrier system was caused by improving its solubility [61]. The last one 2,7-dihydroxy-3,4,9-trimethoxyphenanthrene, obtained from Laelia anceps, caused relaxant activity on norepinephrine precontracted aortic rings with $\mathrm{E}_{\max }$ of $90 \% \pm 1.35 \%$ (with endothelium) and $96.45 \% \pm$ $1.2 \%$ (without endothelium) [74].

\section{Observed Compounds Having BP Lowering Properties}

The discussed antihypertensive compounds, structure demonstrated in Figures 3-7, are 31 types of compounds, such as 1) anthocyanidin (cyanidin-3-O-rutinoside), 2) anthocyanin (anthocyanin fraction), 3) biogenic amine (acetylcholine), 4) catecholamines (L-3,4-dihydroxyphenylalanine), 5) chalcones (marein, coreopsis chalcones), 6) chromenes (methylripariochromene A, acetovanillochromene, orthochromene A), 7) cinnamates (cynarin, caffeic acid, cinnamic acid), 8) coumarins (6,7,8-trimethoxycoumarin, 6,7-dimethoxycoumarin), 9) cyclic acid glucoside (edulilic acid), 10) diarylheptanoid (curcumin), 11) dihydrophenanthrene (2,7-dihydroxy-3,4,9-trimethoxyphenanthrene), 12) flavones (apigenin, vicenin-2, orientin, isoorientin, isovitexin, luteolin), 13) flavonols (quercetin, taxifolin, 3-O-methylquercetine, rutin, quercetine glycosides, 5-hydroxy-3,4',7-tri- methoxyflavone, verbenacoside, isoquercitrin), 14) flavonoid glucosides (tilianin, 


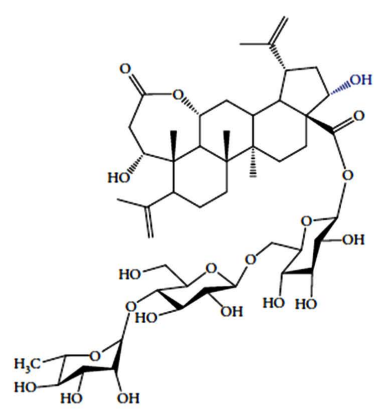

3(a) 22a-hydroxychiisanoside

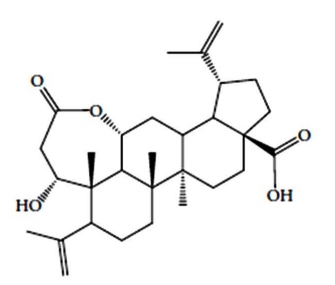

3(d) chiisanogenin<smiles>O=c1cc(-c2ccc(O)cc2)oc2cc(O)cc(O)c12</smiles>

3(g) apigenin

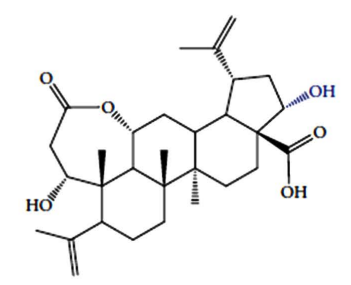

3(b) 22a-hydroxychiisanogenin

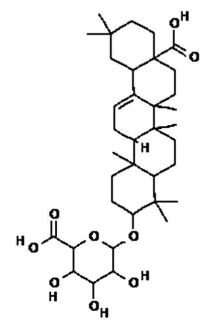

3(e) momordin lb<smiles>O=C(/C=C/c1ccc(O)c(O)c1)OC1C[C@](O)(C(=O)O)C[C@H](O)[C@H]1O</smiles>

3(h) chlorogenic acid

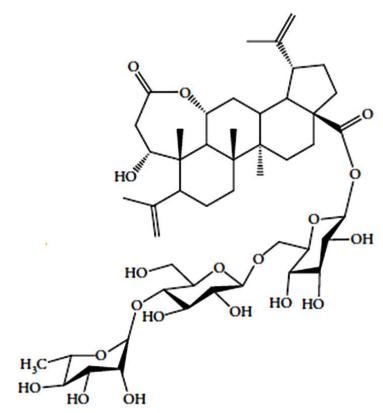

3(c) chiisanoside<smiles>COc1ccc(-c2cc(=O)c3c(O)cc(OC4OC(C)C5OC(C4O)C(O)C5O)cc3o2)cc1</smiles>

3(f) tilianin

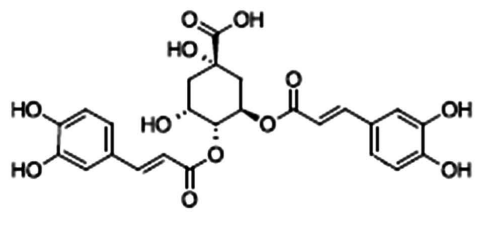

3(i) 3,4-dicaffeoylquinic acid<smiles>O=C(/C=C/c1ccc(O)c(O)c1)O[C@H]1C[C@@](O)(C(=O)O)C(O)C(O)[C@H]1OC(=O)/C=C/c1ccc(O)c(O)c1</smiles>

3(j) 3,5-dicaffeoylquinic acid

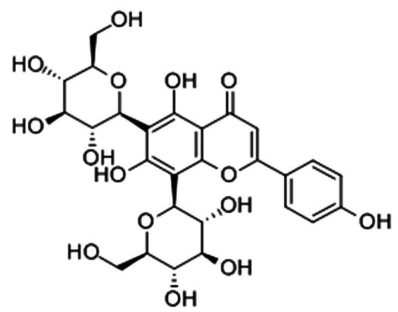

3(I) vicenin-2

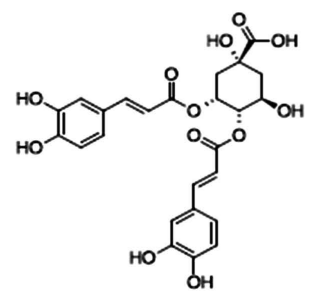

3(k) 4,5-dicaffeoylquinic acid<smiles>COc1ccc2cc3[n+](cc2c1OC)CCc1cc2c(cc1-3)OCO2</smiles>

$3(\mathrm{~m})$ berberine

Figure 3. Reported compounds from medicinal plants manifest anti-hypertensive activity. 


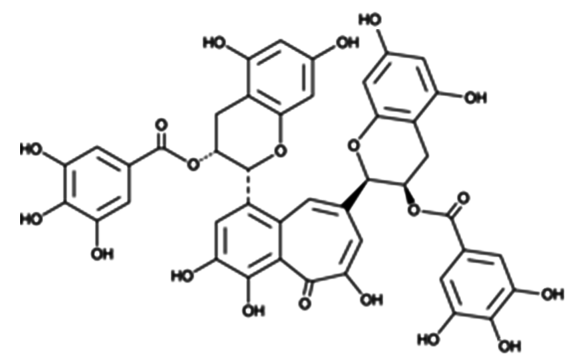

4(a) theaflavin-3,3'-digallate<smiles>Oc1cc(O)c2c(c1)O[C@H](c1ccc(O)c(O)c1)[C@H](O)C2</smiles>

4(d) catechin

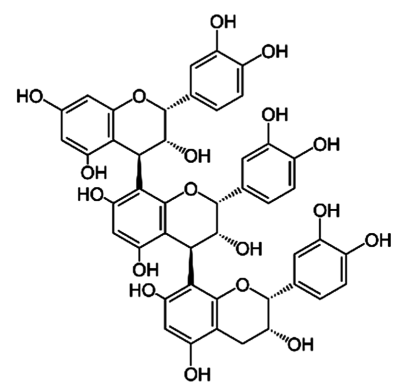

4(g) procyanidin C1

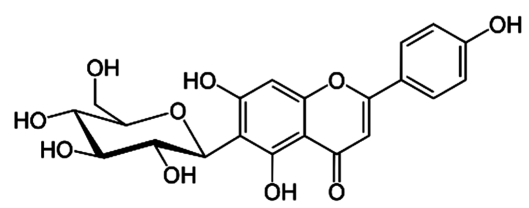

4(j) isovitexin<smiles>Oc1ccc2c(c1)OC(c1ccc(O)c(O)c1)C(O)C2c1c(O)cc2c(c1O)C[C@H](O)[C@H](c1ccc(O)c(O)c1)O2</smiles>

4(b) procyanidin B5<smiles>Oc1cc(O)c2c(c1)O[C@H](c1ccc(O)c(O)c1)[C@H](O)[C@H]2c1c(O)cc(O)c2c1O[C@H](c1ccc(O)c(O)c1)[C@H](O)C2</smiles>

4(e) procyanidin B2<smiles></smiles>

4(h) orientin<smiles>O=c1c(O)c(-c2ccc(O)c(O)c2)oc2cc(O)cc(O)c12</smiles>

4(k) quercetin<smiles>Oc1ccc2c(c1)O[C@H](c1ccc(O)c(O)c1)[C@H](O)[C@H]2c1c(O)cc(O)c2c1O[C@H](c1ccc(O)c(O)c1)[C@@H](O)C2</smiles>

4(c) procyanidin B3<smiles>Oc1cc(O)c2c(c1)O[C@H](c1ccc(O)c(O)c1)[C@H](O)C2</smiles>

4(f) epicatechin<smiles>O=c1cc(-c2ccc(O)c(O)c2)oc2cc(O)c(C3OC4CC(O)C(O)C(O)C3O4)c(O)c12</smiles>

4(i) isoorientin<smiles>O=C1C[C@H](c2ccc(O)cc2)Oc2cc(O)cc(O)c21</smiles>

4(I) naringenin

Figure 4. Reported compounds from medicinal plants manifest anti-hypertensive activity. 
<smiles>COc1cc(/C=C/C(=O)O)ccc1O</smiles>

5(a) ferulic acid

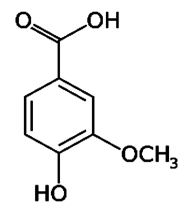

5(b) vanillic acid

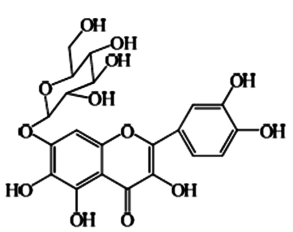

5(c) quercetagetin-7-0-glucoside

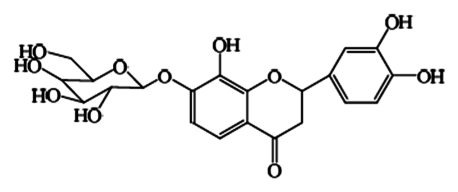

5(d) flavanomarein

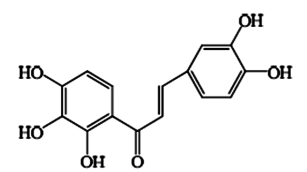

5(g) coreopsis chalcones

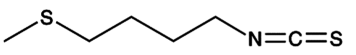

5(j) erucin<smiles>[2H]c1cc(O)c2c(c1)O[C@](C)(c1ccc(O)c(O)c1)C(C)(C)C2=O</smiles>

$\mathrm{R}_{1}=\mathrm{OH}, \mathrm{R}_{2}=\mathrm{H}, \mathrm{R}_{3}=\beta$-D-glucoside $5(\mathrm{~m})$ isosinensin<smiles>COc1c(O)cc2cc(OC)c3cc(O)ccc3c2c1OC</smiles>

5(p) 2,7-dihydroxy-3,4,9trimethoxyphenantrene

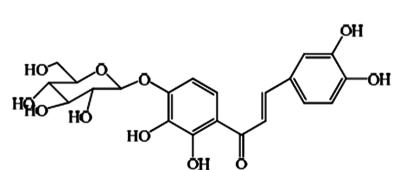

5(e) marein<smiles>O=C(O)c1ccccc1O</smiles>

5(h) phenolic acid<smiles>O=C1C[C@H](c2ccc(O)cc2)Oc2cc(O)cc(O)c21</smiles>

$5(k)$ isoaromadendrin<smiles>COc1c(-c2ccc(O)c(O)c2)oc2cc(O)cc(O)c2c1=O</smiles>

5(n) 3-0-methylquercetine<smiles>COc1cc(CC(COC2O[C@H](CO)[C@@H](O)[C@H](O)C2O)[C@H](COC2OC(CO)[C@@H](O)[C@H](O)C2O)Cc2ccc(O)c(OC)c2)ccc1O</smiles>

5(q) secoisolariciresinol diglucoside<smiles>O=c1cc(-c2ccc(O)c(O)c2)oc2cc(O)cc(O)c12</smiles>

5(f) luteolin<smiles>COc1cc(/C=C/C(=O)/C=C(O)/C=C/c2ccc(O)c(OC)c2)ccc1O</smiles>

5(i) curcumin<smiles>O=C1c2c(O)cc(O)cc2O[C@H](c2ccc(O)c(O)c2)C1O</smiles>

5(I) taxifolin<smiles>O=C(/C=C/c1ccc(O)c(O)c1)OC1CC(OC(=O)/C=C/c2ccc(O)c(O)c2)(C(=O)O)CC(O)[C@H]1O</smiles>

$5(\mathrm{o})$ cynarin<smiles>O=C(O)/C=C/c1ccc(O)c(O)c1</smiles>

$5(r)$ caffeic acid

Figure 5. Reported compounds from medicinal plants manifest anti-hypertensive activity. 
<smiles>O=c1c(-c2ccc(O)cc2)coc2cc(O)cc(O)c12</smiles>

6(a) genistein

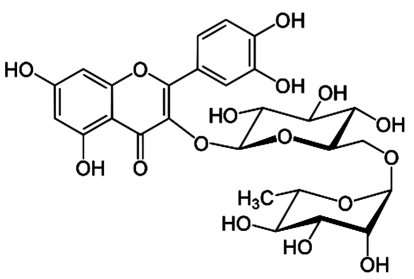

6(d) rutin<smiles>COc1c(C(C)O)cc2c(c1OC)OC(C)(C)C=C2</smiles>

6(g) orthochromene A

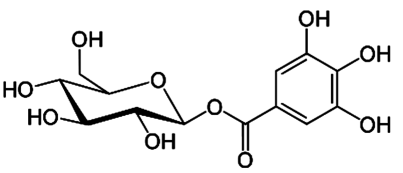

6(j) glucogallin<smiles>COC(=O)c1cc(O)c(O)c(O)c1</smiles>

$6(\mathrm{~m})$ methyl gallate

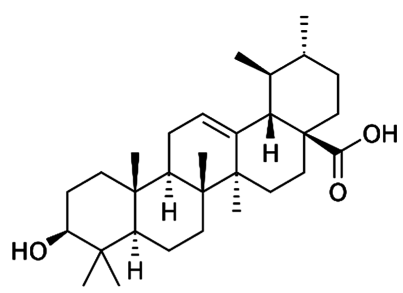

6(b) ursolic acid<smiles>COc1c(C(C)=O)cc2c(c1OC)OC(C)(C)C=C2</smiles>

6(e) methylripariochromene A (MRC)<smiles>O=C(O)C(OC1OC(CO)[C@@H]2O[C@H]1[C@@H](O)[C@H]2O)=C1C=CCC1</smiles>
6(h) edulilic acid<smiles>O=C(O)c1cc(O)c(O)c(O)c1</smiles>

6(k) gallic acid<smiles>N[C@@H](Cc1ccc(O)c(O)c1)C(=O)O</smiles>

6(c) L-DOPA<smiles>COc1cc(C(C)=O)cc2c1OC(C)(C)C=C2</smiles>

6(f) acetovanillochromene<smiles></smiles>

6(i) anthocyanin fraction<smiles>O=C(O)C1=C[C@H](O)[C@H](O)C(OC(=O)c2cc(O)c(O)c(O)c2)C1</smiles>

6(I) galloylshikimic acid

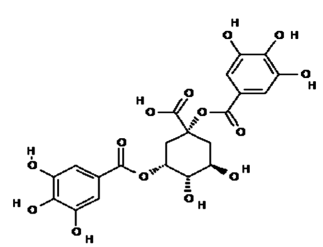

6(n) digalloylquinic acid<smiles>O=C(O)c1cc(O)c(O)c(OC(=O)c2cc(O)c(O)c(O)c2)c1</smiles>

6(o) digallic acid<smiles></smiles>

$6(p)$ trigalloylglucose

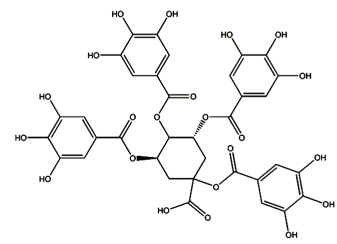

6(q) tetragalloylquinic acid

Figure 6. Reported compounds from medicinal plants manifest anti-hypertensive activity. 


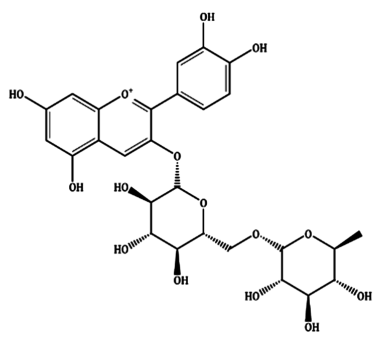

7(a) cyanidin-3-0-rutinoside

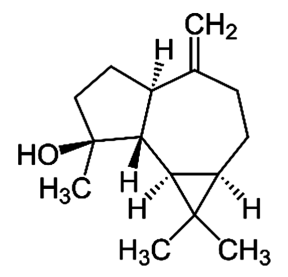

7(d) spathulenol

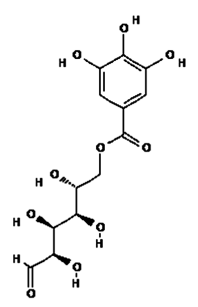

7(g) 6-O-galloyl-D-glucose

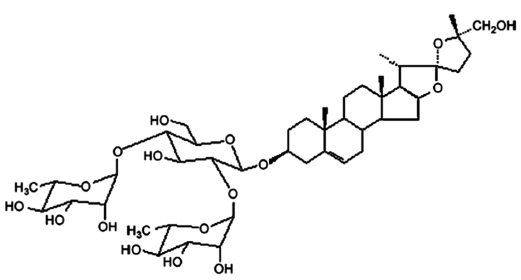

7(j) nuatigenin-3-0- $\beta$-chacotriose

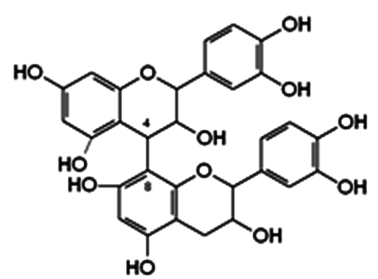

7(b) proanthocyanidins<smiles>COc1cc(O)c2c(=O)cc(-c3ccc(OC)c(OC)c3)oc2c1</smiles>

7(e) 5-hydroxy-3,4',7-trimethoxyflavone<smiles>O=C(O)/C=C/c1ccccc1</smiles>

7(h) cinnamic acid<smiles>COc1cc2ccc(=O)oc2c(OC)c1OC</smiles>

$7($ k) 6,7,8-trimethoxycoumarin<smiles>O=C(O)c1c(-c2ccc(O)cc2)oc2cc(O)cc(O)c12</smiles>

7(c) quercetine glycosides<smiles>[R]c1cc([R20])c2c(=O)c([R])c(-c3ccc([R])c([R])c3)oc2c1</smiles>

$R_{1}=R_{3}=R_{4}=H, R_{2}=O H, R_{5}=\beta$-D-glucoside $7(f)$ verbenacoside<smiles>CC(=O)OCC[N+](C)(C)C</smiles>

7(i) acetylcholine<smiles>COc1cc2ccc(=O)oc2cc1OC</smiles>

7(I) 6,7-dimethoxycoumarin<smiles>O=C(/C=C/c1ccc(O)c(O)c1)OC(Cc1ccc(O)c(O)c1)C(=O)O</smiles>

$7(\mathrm{~m})$ rosmarinic acid

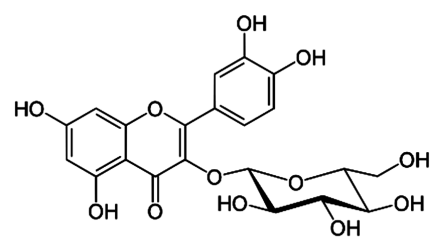

$7(n)$ isoquercitrin

Figure 7. Reported compounds from medicinal plants manifest anti-hypertensive activity. 
quercetagetin-7-O-glucoside, flavanomarein, isosinensin), 15) flavan 3-ols (catechin, epicatechin), 16) flavanones (naringenin, isoaromadendrin), 17) hydroxybenzoate ether (vanillic acid), 18) isoflavone (genistein), 19) isoquinoline alkaloid (berberine), 20) lignan glucoside (secoisolariciresinol diglucoside), 21) phenolic acid, 22) phenylpropanoids (3,4 Dicaffeoylquinic acid, 3,5-Dicaffeoylquinic acid, 4,5-Dicaffeoylquinic acid, chlorogenic acid, ferulic acid, rosmarinic acid), 23) polyphenolic flavonoid (theaflavin-3,3'-digallate), 24) proanthocyanidins (procyanidin $\mathrm{B} 5$, procyanidin $\mathrm{B} 3$, procyanidin $\mathrm{B} 2$, procyanidin $\mathrm{C} 1$ ), 25) sesquiterpenes (spathulenol), 26) steroidal trisaccharide (Nuatigenin-3-O- $\beta$ chacotriose), 27) tannins and galloyl derivatives (glucogallin, gallic acid, galloylshikimic acid, methyl gallate, digalloylquinic acid, digallic acid, trigalloylglucose, tetragalloylquinic acid, 6-O-galloyl-D-glucose), 28) thiocyanate (erucin), 29) triterpene (momordin $\mathrm{Ib}$ ), 30) triterpenoids (22 $\alpha$-hydroxychiisanogenin, chiisanogenin, ursolic acid), and 31) triterpenoid saponins (22 $\alpha$-hydroxychiisanoside, chiisanoside). Highest number of compounds are tannins and galloyl derivatives, flavonols, flavones, phenylpropanoids, proanthocyanidins and flavonoid glucosides.

Structure of the compounds reveals that most of the compounds possess heterocyclic oxygen atom which is thought to exert the desired antihypertensive or antioxidative activities. The possible way would be chelating with the zinc atom present in the center of the ACE I.

\section{Conclusion}

The goal of our research is to let everyone know that there are an ample number of natural compounds that can be made into antihypertensive therapies. We noticed that the majority of the researches focused on the effect of the extracts on antihypertensive therapy along with the mechanism of action and more than half of them elucidated structures of compounds responsible for the activity. As a result, expanding studies into mechanisms and structure elucidation can contribute to the development of new drugs. 63 plant species from 37 families and 74 isolated compounds are reviewed here. Among them, tilianin, naringenin, curcumin nanoemulsion, 2,7-dihydroxy-3,4,9-trimethoxyphenanthrene are the topmost candidate for producing antihypertensive therapy from natural products in a safe, efficient, and patient adhering way. On the other hand, relaxation of blood vessels, formation of NO, blockage of calcium channels, increase in potassium, suppression of the renin-angiotensin pathway, activation of intracellular cGMP, and inactivation of the sympathetic system are mostly the mechanisms discovered in these medicinal plants for antihypertensive activity. Depending upon the side effects of the ongoing therapies, we think it is high time that the pharmaceuticals took the appropriate steps to synthesize effective drug candidate from these phytochemicals that can reach every human being's doorway. Further studies of the rest of the compounds could also lead to promising antihypertensive therapies. 


\section{Conflicts of Interest}

The authors declare no conflicts of interest regarding the publication of this paper.

\section{References}

[1] Williams, B., Mancia, G., Spiering, W., Agabiti Rosei, E., Azizi, M., Burnier, M., Clement, D.L., Coca, A., de Simone, G., Dominiczak, A., Kahan, T., Mahfoud, F., Redon, J., Ruilope, L., Zanchetti, A., Kerins, M., Kjeldsen, S.E., Kreutz, R., Laurent, S., Lip, G.Y.H., McManus, R., Narkiewicz, K., Ruschitzka, F., Schmieder, R.E., Shlyakhto, E., Tsioufis, C., Aboyans, V., Desormais, I. and ESC Scientific Document Group (2018) 2018 ESC/ESH Guidelines for the Management of Arterial Hypertension: The Task Force for the Management of Arterial Hypertension of the European Society of Cardiology (ESC) and the European Society of Hypertension (ESH). European Heart Journal, 39, 3021-3104. https://doi.org/10.1093/eurheartj/ehy339

[2] Aggarwal, M. and Khan, I.A. (2006) Hypertensive Crisis: Hypertensive Emergencies and Urgencies. Cardiology Clinics, 24, 135-146.

https://doi.org/10.1016/j.ccl.2005.09.002

[3] Abegaz, T.M., Shehab, A., Gebreyohannes, E.A., Bhagavathula, A.S. and Elnour, A.A. (2017) Nonadherence to Antihypertensive Drugs. Medicine, 96, e5641. https://doi.org/10.1097/MD.0000000000005641

[4] Kearney, P.M., Whelton, M., Reynolds, K., Muntner, P., Whelton, P.K. and He, J. (2005) Global Burden of Hypertension: Analysis of Worldwide Data. The Lancet, 365, 217-223. https://doi.org/10.1016/S0140-6736(05)17741-1

[5] Pierdomenico, S.D., Di Nicola, M., Esposito, A.L., Di Mascio, R., Ballone, E., Lapenna, D. and Cuccurullo, F. (2009) Prognostic Value of Different Indices of Blood Pressure Variability in Hypertensive Patients. American Journal of Hypertension, 22, 842-847. https://doi.org/10.1038/ajh.2009.103

[6] Whelton, P.K., He, J., Appel, L.J., Cutler, J.A., Havas, S., Kotchen, T.A., Roccella, E.J., Stout, R., Vallbona, C., Winston, M.C., Karimbakas, J. and for the National High Blood Pressure Education Program Coordinating Committee (2002) Primary Prevention of Hypertension Clinical and Public Health Advisory from the National High Blood Pressure Education Program. JAMA, 288, 1882-1888. https://doi.org/10.1001/jama.288.15.1882

[7] Staffileno, B.A. (2005) Treating Hypertension with Cardioprotective Therapies: The Role of ACE Inhibitors, ARBs, and $\beta$-Blockers. Journal of Cardiovascular Nursing, 20, 354-364. https://doi.org/10.1097/00005082-200509000-00010

[8] Niaz, T., Hafeez, Z. and Imran, M. (2017) Prospectives of Antihypertensive Nano-ceuticals as Alternative Therapeutics. Current Drug Targets, 18, 1269-1280. https://doi.org/10.2174/1389450117666160711163119

[9] Hermann, M., Flammer, A. and Lscher, T.F. (2006) Nitric Oxide in Hypertension. The Journal of Clinical Hypertension, 8, 17-29. https://doi.org/10.1111/j.1524-6175.2006.06032.x

[10] Landmesser, U. and Drexler, H. (2007) Endothelial Function and Hypertension. Current Opinion in Cardiology, 22, 316-320. https://doi.org/10.1097/HCO.0b013e3281ca710d

[11] Farah, C., Michel, L.Y.M. and Balligand, J.-L. (2018) Nitric Oxide Signalling in Cardiovascular Health and Disease. Nature Reviews Cardiology, 15, 292-316. https://doi.org/10.1038/nrcardio.2017.224 
[12] Alp Yildirim, F.I., Eker Kizilay, D., Ergin, B., Balci Ekmekçi, Ö., Topal, G., Kucur, M., Demirci Tansel, C. and Uydeş Doğan, B.S. (2015) Barnidipine Ameliorates the Vascular and Renal Injury in l-NAME-Induced Hypertensive Rats. European Journal of Pharmacology, 764, 433-442. https://doi.org/10.1016/j.ejphar.2015.07.033

[13] Maneesai, P., Prasarttong, P., Bunbupha, S., Kukongviriyapan, U., Kukongviriyapan, V., Tangsucharit, P., Prachaney, P. and Pakdeechote, P. (2016) Synergistic Antihypertensive Effect of Carthamus tinctorius L. Extract and Captopril in 1-NAME-Induced Hypertensive Rats via Restoration of ENOS and $\mathrm{AT}_{1} \mathrm{R}$ Expression. Nutrients, 8, 122. https://doi.org/10.3390/nu8030122

[14] Katzung, B.G., Masters, S.B. and Trevor, A.J., Eds. (2012) Basic and Clinical Pharmacology. 12th Edition, McGraw-Hill Medical, New York.

[15] Rodríguez-Rodríguez, P., Ramiro-Cortijo, D., Reyes-Hernández, C.G., López de Pablo, A.L., González, M.C. and Arribas, S.M. (2018) Implication of Oxidative Stress in Fetal Programming of Cardiovascular Disease. Frontiers in Physiology, 9, 602. https://doi.org/10.3389/fphys.2018.00602

[16] Saravanakumar, M. and Raja, B. (2011) Veratric Acid, a Phenolic Acid Attenuates Blood Pressure and Oxidative Stress in l-NAME Induced Hypertensive Rats. European Journal of Pharmacology, 671, 87-94. https://doi.org/10.1016/j.ejphar.2011.08.052

[17] Poasakate, A., Tong-un, T., Ishida, W., Prachaney, P., Maneesai, P., Potue, P. and Pakdeechote, P. (2019) Effect of Cratoxylum formosum Dyer Extract on Sperm Motility and Concentration in L-NAME Hypertensive Rats. Srinagarind Medical Journal, 34, 312-317.

[18] Wunpathe, C., Maneesai, P., Rattanakanokchai, S., Bunbupha, S., Kukongviriyapan, U., Tong-un, T. and Pakdeechote, P. (2020) Tangeretin Mitigates L-NAME-Induced Ventricular Dysfunction and Remodeling through the AT R/PERK1/2/PJNK Signaling Pathway in Rats. Food \& Function, 11, 1322-1333.

https://doi.org/10.1039/C9FO02365H

[19] Pacher, P., Beckman, J.S. and Liaudet, L. (2007) Nitric Oxide and Peroxynitrite in Health and Disease. Physiological Reviews, 87, 315-424.

https://doi.org/10.1152/physrev.00029.2006

[20] Rincón, J., Correia, D., Arcaya, J.L., Finol, E., Fernández, A., Pérez, M., Yaguas, K., Talavera, E., Chávez, M., Summer, R. and Romero, F. (2015) Role of Angiotensin II Type 1 Receptor on Renal NAD(P)H Oxidase, Oxidative Stress and Inflammation in Nitric Oxide Inhibition Induced-Hypertension. Life Sciences, 124, 81-90. https://doi.org/10.1016/j.lfs.2015.01.005

[21] Sonoda, K., Ohtake, K., Uchida, H., Ito, J., Uchida, M., Natsume, H., Tamada, H. and Kobayashi, J. (2017) Dietary Nitrite Supplementation Attenuates Cardiac Remodeling in 1-NAME-Induced Hypertensive Rats. Nitric Oxide, 67, 1-9. https://doi.org/10.1016/j.niox.2017.04.009

[22] Genest, J. (1961) Angiotensin, Aldosterone and Human Arterial Hypertension. Canadian Medical Association Journal, 84, 403-419.

[23] Johnson, R.A. and Freeman, R.H. (1994) Renin Release in Rats during Blockade of Nitric Oxide Synthesis. American Journal of Physiology-Regulatory, Integrative and Comparative Physiology, 266, R1723-R1729. https://doi.org/10.1152/ajpregu.1994.266.6.R1723

[24] Pollock, D.M., Polakowski, J.S., Divish, B.J. and Opgenorth, T.J. (1993) Angiotensin Blockade Reverses Hypertension during Long-Term Nitric Oxide Synthase Inhibition. Hypertension, 21, 660-666. https://doi.org/10.1161/01.HYP.21.5.660 
[25] Gao, Y., Wang, Z., Zhang, Y., Liu, Y., Wang, S., Sun, W., Guo, J., Yu, C., Wang, Y., Kong, W. and Zheng, J. (2018) Naringenin Inhibits NG-Nitro-L-Arginine Methyl Ester-Induced Hypertensive Left Ventricular Hypertrophy by Decreasing Angiotensin-Converting Enzyme 1 Expression. Experimental and Therapeutic Medicine, 16, 867-873. https://doi.org/10.3892/etm.2018.6258

[26] Okazaki, H., Minamino, T., Tsukamoto, O., Kim, J., Okada, K., Myoishi, M., Wakeno, M., Takashima, S., Mochizuki, N. and Kitakaze, M. (2006) Angiotensin II Type 1 Receptor Blocker Prevents Atrial Structural Remodeling in Rats with Hypertension Induced by Chronic Nitric Oxide Inhibition. Hypertension Research, 29, 277-284. https://doi.org/10.1291/hypres.29.277

[27] Dugourd, C., Gervais, M., Corvol, P. and Monnot, C. (2003) Akt Is a Major Downstream Target of PI3-Kinase Involved in Angiotensin II-Induced Proliferation. Hypertension, 41, 882-890. https://doi.org/10.1161/01.HYP.0000060821.62417.35

[28] Touyz, R.M. and Berry, C. (2002) Recent Advances in Angiotensin II Signaling. Brazilian Journal of Medical and Biological Research, 35, 1001-1015. https://doi.org/10.1590/S0100-879X2002000900001

[29] de Kloet, A.D., Krause, E.G., Shi, P.D., Zubcevic, J., Raizada, M.K. and Sumners, C. (2013) Neuroimmune Communication in Hypertension and Obesity: A New Therapeutic Angle? Pharmacology \& Therapeutics, 138, 428-440. https://doi.org/10.1016/j.pharmthera.2013.02.005

[30] Taylor, D.A. and Abdel-Rahman, A.A. (2009) Novel Strategies and Targets for the Management of Hypertension. In: Enna, S.J. and Williams, M., Eds., Advances in Pharmacology, Vol. 57, Elsevier Inc., Amsterdam, 291-345. https://doi.org/10.1016/S1054-3589(08)57008-6

[31] Lonn, E. (2004) The Clinical Relevance of Pharmacological Blood Pressure Lowering Mechanisms. The Canadian Journal of Cardiology, 20, 83B-88B.

https://pubmed.ncbi.nlm.nih.gov/15309210/

[32] Kagathara, V.G., Ambikar, D.B. and Vyawahare, N.S. (2009) Hypertension-Animal Models and Phytomedicines: A Review. Pharmacologyonline, 2, 436-461. https://pharmacologyonline.silae.it/front/newsletter 20092

[33] Wood, R. (1995) Bronchospasm and Cough as Adverse Reactions to the ACE Inhibitors Captopril, Enalapril and Lisinopril. A Controlled Retrospective Cohort Study. British Journal of Clinical Pharmacology, 39, 265-270. https://doi.org/10.1111/j.1365-2125.1995.tb04447.x

[34] Hom, K.A., Hirsch, R. and Elluru, R.G. (2012) Antihypertensive Drug-Induced Angioedema Causing Upper Airway Obstruction in Children. International Journal of Pediatric Otorhinolaryngology, 76, 14-19. https://doi.org/10.1016/j.ijporl.2011.07.016

[35] Shapovalov, G., Skryma, R. and Prevarskaya, N. (2013) Calcium Channels and Prostate Cancer. Recent Patents on Anti-Cancer Drug Discovery, 8, 18-26. https://doi.org/10.2174/1574892811308010018

[36] McAinsh, J. and Cruickshank, J.M. (1990) Beta-Blockers and Central Nervous System Side Effects. Pharmacology \& Therapeutics, 46, 163-197. https://doi.org/10.1016/0163-7258(90)90092-G

[37] Özkaya, E. and Yazganoğlu, K.D. (2014) Adverse Cutaneous Drug Reactions to Cardiovascular Drugs. Springer London, London. https://doi.org/10.1007/978-1-4471-6536-1

[38] Pal, S.K. and Shukla, Y. (2003) Herbal Medicine: Current Status and the Future. Asian Pacific Journal of Cancer Prevention, 4, 281-288. 
[39] Valli, G. and Giardina, E.-G.V. (2002) Benefits, Adverse Effects and Drug Interactions of Herbal Therapies with Cardiovascular Effects. Journal of the American College of Cardiology, 39, 1083-1095. https://doi.org/10.1016/S0735-1097(02)01749-7

[40] Jung, I.H., Kim, S.E., Lee, Y.-G., Kim, D.H., Kim, H., Kim, G.-S., Baek, N.-I. and Lee, D.Y. (2018) Antihypertensive Effect of Ethanolic Extract from Acanthopanax sessiliflorus Fruits and Quality Control of Active Compounds. Oxidative Medicine and Cellular Longevity, 2018, Article: ID 5158243.

https://doi.org/10.1155/2018/5158243

[41] Hernández-Abreu, O., Torres-Piedra, M., García-Jiménez, S., Ibarra-Barajas, M., Villalobos-Molina, R., Montes, S., Rembao, D. and Estrada-Soto, S. (2013) Dose-Dependent Antihypertensive Determination and Toxicological Studies of Tilianin Isolated from Agastache mexicana. Journal of Ethnopharmacology, 146, 187-191.

https://doi.org/10.1016/j.jep.2012.12.029

[42] Bilanda, D.C., Dimo, T., Dzeufiet Djomeni, P.D., Bella, N.M.T., Aboubakar, O.B.F., Nguelefack, T.B., Tan, P.V. and Kamtchouing, P. (2010) Antihypertensive and Antioxidant Effects of Allanblackia floribunda Oliv. (Clusiaceae) Aqueous Extract in Alcohol- and Sucrose-Induced Hypertensive Rats. Journal of Ethnopharmacology, 128, 634-640. https://doi.org/10.1016/j.jep.2010.02.025

[43] Bello, I., Usman, N.S., Mahmud, R. and Asmawi, Mohd.Z. (2015) Mechanisms Underlying the Antihypertensive Effect of Alstonia scholaris. Journal of Ethnopharmacology, 175, 422-431. https://doi.org/10.1016/j.jep.2015.09.031

[44] Jorge, V.-G., Ángel, J.-R.L., Adrián, T.-S., Francisco, A.-C., Anuar, S.-G., Samuel, E.-S., Ángel, S.-O. and Emmanuel, H.-N. (2013) Vasorelaxant Activity of Extracts Obtained from Apium graveolens. Possible Source for Vasorelaxant Molecules Isolation with Potential Antihypertensive Effect. Asian Pacific Journal of Tropical Biomedicine, 3, 776-779. https://doi.org/10.1016/S2221-1691(13)60154-9

[45] Inokuchi, J., Okabe, H., Yamauchi, T., Nonaka, G. and Nishioka, I. (1986) Antihypertensive Substance in Seeds of Areca catechu L. Life Sciences, 38, 1375-1382. https://doi.org/10.1016/0024-3205(86)90470-4

[46] Dib, I., Tits, M., Angenot, L., Wauters, J.N., Assaidi, A., Mekhfi, H., Aziz, M., Bnouham, M., Legssyer, A., Frederich, M. and Ziyyat, A. (2017) Antihypertensive and Vasorelaxant Effects of Aqueous Extract of Artemisia campestris L. from Eastern Morocco. Journal of Ethnopharmacology, 206, 224-235. https://doi.org/10.1016/j.jep.2017.05.036

[47] Abd El-Wahab, A.E., Ghareeb, D.A., Sarhan, E.E., Abu-Serie, M.M. and El Demellawy, M.A. (2013) In Vitro Biological Assessment of Berberis vulgaris and Its Active Constituent, Berberine: Antioxidants, Anti-Acetylcholinesterase, Anti-Diabetic and Anticancer Effects. BMC Complementary and Alternative Medicine, 13, Article No. 218. https://doi.org/10.1186/1472-6882-13-218

[48] Getiye, Y., Tolessa, T. and Engidawork, E. (2016) Antihypertensive Activity of $80 \%$ Methanol Seed Extract of Calpurnia aurea (Ait.) Benth. subsp. aurea (Fabaceae) Is Mediated through Calcium Antagonism Induced Vasodilation. Journal of Ethnopharmacology, 189, 99-106. https://doi.org/10.1016/j.jep.2016.04.056

[49] Cheang, W.S., Ngai, C.Y., Tam, Y.Y., Tian, X.Y., Wong, W.T., Zhang, Y., Lau, C.W., Chen, Z.Y., Bian, Z.-X., Huang, Y. and Leung, F.P. (2015) Black Tea Protects against Hypertension-Associated Endothelial Dysfunction through Alleviation of Endoplasmic Reticulum Stress. Scientific Reports, 5, Article No. 10340. https://doi.org/10.1038/srep10340

[50] Lima-Landman, M.T.R., Borges, A.C.R., Cysneiros, R.M., De Lima, T.C.M., Souc- 
car, C. and Lapa, A.J. (2007) Antihypertensive Effect of a Standardized Aqueous Extract of Cecropia glaziovii Sneth in Rats: An in Vivo Approach to the Hypotensive Mechanism. Phytomedicine, 14, 314-320.

https://doi.org/10.1016/j.phymed.2007.03.003

[51] Belmokhtar, M., Bouanani, N.E., Ziyyat, A., Mekhfi, H., Bnouham, M., Aziz, M., Matéo, P., Fischmeister, R. and Legssyer, A. (2009) Antihypertensive and Endothelium-Dependent Vasodilator Effects of Aqueous Extract of Cistus ladaniferus. Biochemical and Biophysical Research Communications, 389, 145-149.

https://doi.org/10.1016/j.bbrc.2009.08.113

[52] Guerrero, L., Castillo, J., Quiñones, M., Garcia-Vallvé, S., Arola, L., Pujadas, G. and Muguerza, B. (2012) Inhibition of Angiotensin-Converting Enzyme Activity by Flavonoids: Structure-Activity Relationship Studies. PLoS ONE, 7, e49493.

https://doi.org/10.1371/journal.pone.0049493

[53] Loizzo, M.R., Said, A., Tundis, R., Rashed, K., Statti, G.A., Hufner, A. and Menichini, F. (2007) Inhibition of Angiotensin Converting Enzyme (ACE) by Flavonoids Isolated from Ailanthus excelsa (Roxb) (Simaroubaceae). Phytotherapy Research, 21, 32-36. https://doi.org/10.1002/ptr.2008

[54] Escher, G.B., Marques, M.B., do Carmo, M.A.V., Azevedo, L., Furtado, M.M., Sant'Ana, A.S., da Silva, M.C., Genovese, M.I., Wen, M., Zhang, L., Oh, W.Y., Shahidi, F., Rosso, N.D. and Granato, D. (2020) Clitoria ternatea L. Petal Bioactive Compounds Display Antioxidant, Antihemolytic and Antihypertensive Effects, Inhibit $\alpha$-Amylase and $\alpha$-Glucosidase Activities and Reduce Human LDL Cholesterol and DNA Induced Oxidation. Food Research International, 128, Article ID: 108763. https://doi.org/10.1016/j.foodres.2019.108763

[55] Sánchez-Salgado, J.C., Castillo-España, P., Ibarra-Barajas, M., Villalobos-Molina, R. and Estrada-Soto, S. (2010) Cochlospermum vitifolium Induces Vasorelaxant and Antihypertensive Effects Mainly by Activation of NO/CGMP Signaling Pathway. Journal of Ethnopharmacology, 130, 477-484.

https://doi.org/10.1016/j.jep.2010.05.037

[56] Bankar, G.R., Nayak, P.G., Bansal, P., Paul, P., Pai, K.S.R., Singla, R.K. and Bhat, V.G. (2011) Vasorelaxant and Antihypertensive Effect of Cocos nucifera Linn. Endocarp on Isolated Rat Thoracic Aorta and DOCA Salt-Induced Hypertensive Rats. Journal of Ethnopharmacology, 134, 50-54.

https://doi.org/10.1016/i.jep.2010.11.047

[57] Yang, Q., Sun, Y., Zhang, L., Xu, L., Hu, M., Liu, X., Shi, F. and Gu, Z. (2014) Antihypertensive Effects of Extract from Flower Buds of Coreopsis tinctoria on Spontaneously Hypertensive Rats. Chinese Herbal Medicines, 6, 103-109. https://doi.org/10.1016/S1674-6384(14)60015-0

[58] Potue, P., Maneesai, P., Kukongviriyapan, U., Prachaney, P. and Pakdeechote, P. (2020) Cratoxylum formosum Extract Exhibits Antihypertensive Effects via Suppressing the Renin-Angiotensin Cascade in Hypertensive Rats. Journal of Functional Foods, 73, Article ID: 104137. https://doi.org/10.1016/j.jff.2020.104137

[59] Guerrero, M.F., Carrón, R., Martín, M.L., San Román, L. and Reguero, M.T. (2001) Antihypertensive and Vasorelaxant Effects of Aqueous Extract from Croton schiedeanus Schlecht in Rats. Journal of Ethnopharmacology, 75, 33-36. https://doi.org/10.1016/S0378-8741(00)00391-3

[60] Shin, S.-K., Ha, T.-Y., McGregor, R.A. and Choi, M.-S. (2011) Long-Term Curcumin Administration Protects against Atherosclerosis via Hepatic Regulation of Lipoprotein Cholesterol Metabolism. Molecular Nutrition \& Food Research, 55, 1829-1840. https://doi.org/10.1002/mnfr.201100440 
[61] Rachmawati, H. (2016) In Vitro Study on Antihypertensive and Antihypercholesterolemic Effects of Curcumin Nanoemulsion. Scientia Pharmaceutica, 84, 131-140. https://doi.org/10.3797/scipharm.ISP.2015.05

[62] Prando, T.B.L., Barboza, L.N., de OliveiraAraújo, V., Gasparotto, F.M., de Souza, L.M., Lourenço, E.L.B. and Gasparotto Junior, A. (2016) Involvement of Bradykinin B2 and Muscarinic Receptors in the Prolonged Diuretic and Antihypertensive Properties of Echinodorus grandiflorus (Cham. \& Schltdl.) Micheli. Phytomedicine, 23, 1249-1258. https://doi.org/10.1016/j.phymed.2015.10.020

[63] Salma, U., Khan, T. and Shah, A.J. (2018) Antihypertensive Effect of the Methanolic Extract from Eruca sativa Mill., (Brassicaceae) in Rats: Muscarinic Receptor-Linked Vasorelaxant and Cardiotonic Effects. Journal of Ethnopharmacology, 224, 409-420. https://doi.org/10.1016/j.jep.2018.06.013

[64] Eka, M.E.B., Itam, E.H., Eyonng, E.U., Anam, E.M. and Nsa, E.E. (2011) Effect of Erythrina senegalensis Extract on Serum Glucose Concentration in Alloxan Induced Diabetic Rats after a Treatment Period of 14 Days. Multidisciplinary Journal of Research Development, 17, 110-113. https://www.globalacademicgroup.com/node/367

[65] Jiang, C., Liang, L. and Guo, Y. (2012) Natural Products Possessing Protein Tyrosine Phosphatase 1B (PTP1B) Inhibitory Activity Found in the Last Decades. Acta Pharmacologica Sinica, 33, 1217-1245. https://doi.org/10.1038/aps.2012.90

[66] Bilanda, D.C., Bidingha, R. à G., Djomeni Dzeufiet, P.D., Fouda, Y.B., Ngapout, R.F., Tcheutchoua, Y., Owona, P.E., Njonte Wouamba, S.C., Tanfack Tatchou, L., Dimo, T. and Kamtchouing, P. (2020) Antihypertensive and Antidiabetic Activities of Erythrina senegalensis DC (Fabaceae) Stem Bark Aqueous Extract on Diabetic Hypertensive Rats. Journal of Ethnopharmacology, 246, Article ID: 112200. https://doi.org/10.1016/j.jep.2019.112200

[67] Luo, L., Wu, W., Zhou, Y., Yan, J., Yang, G. and Ouyang, D. (2010) Antihypertensive Effect of Eucommia ulmoides Oliv. Extracts in Spontaneously Hypertensive Rats. Journal of Ethnopharmacology, 129, 238-243.

https://doi.org/10.1016/j.jep.2010.03.019

[68] Consolini, A.E., Baldini, O.A.N. and Amat, A.G. (1999) Pharmacological Basis for the Empirical Use of Eugenia uniflora L. (Myrtaceae) as Antihypertensive. Journal of Ethnopharmacology, 66, 33-39. https://doi.org/10.1016/S0378-8741(98)00194-9

[69] Ahmed, B., Al-Howiriny, T.A., Mossa, J.S. and El Tahir, K.E.H. (2005) Isolation, Antihypertensive Activity and Structure Activity Relationship of Flavonoids from Three Medicinal Plants. Indian Journal of Chemistry-Section B, 44B, 400-404. http://nopr.niscair.res.in/handle/123456789/8947 https://doi.org/10.1002/chin.200525220

[70] Hakkou, Z., Maciuk, A., Leblais, V., Bouanani, N.E., Mekhfi, H., Bnouham, M., Aziz, M., Ziyyat, A., Rauf, A., Hadda, T.B., Shaheen, U., Patel, S., Fischmeister, R. and Legssyer, A. (2017) Antihypertensive and Vasodilator Effects of Methanolic Extract of Inula viscosa: Biological Evaluation and POM Analysis of Cynarin, Chlorogenic Acid as Potential Hypertensive. Biomedicine \& Pharmacotherapy, 93, 62-69. https://doi.org/10.1016/j.biopha.2017.06.015

[71] Chaudhry, M.A., Alamgeer, Mushtaq, M.N., Bukhari, I.A. and Assiri, A.M. (2021) Ipomoea hederacea Jacq.: A Plant with Promising Antihypertensive and Cardio-Protective Effects. Journal of Ethnopharmacology, 268, Article ID: 113584. https://doi.org/10.1016/j.jep.2020.113584

[72] Wilcox, C.S. (2005) Oxidative Stress and Nitric Oxide Deficiency in the Kidney: A Critical Link to Hypertension? American Journal of Physiology: Regulatory, Inte- 
grative and Comparative Physiology, 289, R913-R935.

https://doi.org/10.1152/ajpregu.00250.2005

[73] Bopda, O.S.M., Longo, F., Bella, T.N., Edzah, P.M.O., Taïwe, G.S., Bilanda, D.C., Tom, E.N.L., Kamtchouing, P. and Dimo, T. (2014) Antihypertensive Activities of the Aqueous Extract of Kalanchoe pinnata (Crassulaceae) in High Salt-Loaded Rats. Journal of Ethnopharmacology, 153, 400-407.

https://doi.org/10.1016/j.jep.2014.02.041

[74] Vergara-Galicia, J., Ortiz-Andrade, R., Rivera-Leyva, J., Castillo-España, P., Villalobos-Molina, R., Ibarra-Barajas, M., Gallardo-Ortiz, I. and Estrada-Soto, S. (2010) Vasorelaxant and Antihypertensive Effects of Methanolic Extract from Roots of Laelia anceps Are Mediated by Calcium-Channel Antagonism. Fitoterapia, 81, 350-357. https://doi.org/10.1016/j.fitote.2009.10.009

[75] Vergara-Galicia, J., Ortiz-Andrade, R., Castillo-España, P., Ibarra-Barajas, M., Gallardo-Ortiz, I., Villalobos-Molina, R. and Estrada-Soto, S. (2008) Antihypertensive and Vasorelaxant Activities of Laelia autumnalis Are Mainly through Calcium Channel Blockade. Vascular Pharmacology, 49, 26-31. https://doi.org/10.1016/j.vph.2008.04.002

[76] Maghrani, M., Zeggwagh, N.-A., Michel, J.-B. and Eddouks, M. (2005) Antihypertensive Effect of Lepidium sativum L. in Spontaneously Hypertensive Rats. Journal of Ethnopharmacology, 100, 193-197. https://doi.org/10.1016/j.jep.2005.02.024

[77] Prasad, K. (2004) Antihypertensive Activity of Secoisolariciresinol Diglucoside (SDG) Isolated from Flaxseed: Role of Guanylate Cyclase. International Journal of Angiology, 13, 7-14. https://doi.org/10.1007/s00547-004-1060-4

[78] Suzuki, A., Kagawa, D., Fujii, A., Ochiai, R., Tokimitsu, I. and Saito, I. (2002) Shortand Long-Term Effects of Ferulic Acid on Blood Pressure in Spontaneously Hypertensive Rats. American Journal of Hypertension, 15, 351-357.

https://doi.org/10.1016/S0895-7061(01)02337-8

[79] Veeramani, C., Al-Numair, K.S., Chandramohan, G., Alsaif, M.A., Alhamdan, A.A. and Pugalendi, K.V. (2012) Antihypertensive Effect of Melothria maderaspatana Leaf Fractions on DOCA-Salt-Induced Hypertensive Rats and Identification of Compounds by GC-MS Analysis. Journal of Natural Medicines, 66, 302-310. https://doi.org/10.1007/s11418-011-0590-2

[80] Yeh, C.-T., Huang, W.-H. and Yen, G.-C. (2009) Antihypertensive Effects of Hsian-Tsao and Its Active Compound in Spontaneously Hypertensive Rats. The Journal of Nutritional Biochemistry, 20, 866-875. https://doi.org/10.1016/j.jnutbio.2008.07.015

[81] Dangi, S.Y., Jolly, C.I. and Narayanan, S. (2002) Antihypertensive Activity of the Total Alkaloids from the Leaves of Moringa oleifera. Pharmaceutical Biology, 40, 144-148. https://doi.org/10.1076/phbi.40.2.144.5847

[82] Khan, M.Y. and Kumar, V. (2017) Mechanism of Antihypertensive Effect of Mucuna pruriens L. Seed Extract and Its Isolated Compounds. Journal of Complementary and Integrative Medicine, 14, Article ID: 20170014.

https://doi.org/10.1515/jcim-2017-0014

[83] Alu'datt, M.H., Rababah, T., Alhamad, M.N., Gammoh, S., Ereifej, K., Alodat, M., Hussein, N.M., Kubow, S. and Torley, P.J. (2016) Antioxidant and Antihypertensive Properties of Phenolic-Protein Complexes in Extracted Protein Fractions from $\mathrm{Ni}$ gella damascena and Nigella arvensis. Food Hydrocolloids, 56, 84-92. https://doi.org/10.1016/j.foodhyd.2015.12.008

[84] Shaw, H.-M., Wu, J.-L. and Wang, M.-S. (2017) Antihypertensive Effects of Oci- 
mum gratissimum Extract: Angiotensin-Converting Enzyme Inhibitor in Vitro and in Vivo Investigation. Journal of Functional Foods, 35, 68-73. https://doi.org/10.1016/j.jff.2017.05.033

[85] Alcaide-Hidalgo, J.M., Margalef, M., Bravo, F.I., Muguerza, B. and López-Huertas, E. (2020) Virgin Olive Oil (Unfiltered) Extract Contains Peptides and Possesses ACE Inhibitory and Antihypertensive Activity. Clinical Nutrition, 39, 1242-1249. https://doi.org/10.1016/j.clnu.2019.05.016

[86] Matsubara, T., Bohgaki, T., Watarai, M., Suzuki, H., Ohashi, K. and Shibuya, H. (1999) Antihypertensive Actions of Methylripariochromene A from Orthosiphon aristatus, an Indonesian Traditional Medicinal Plant. Biological and Pharmaceutical Bulletin, 22, 1083-1088. https://doi.org/10.1248/bpb.22.1083

[87] Siow, H.-L. and Gan, C.-Y. (2013) Extraction of Antioxidative and Antihypertensive Bioactive Peptides from Parkia speciosa Seeds. Food Chemistry, 141, 3435-3442. https://doi.org/10.1016/j.foodchem.2013.06.030

[88] Lewis, B.J., Herrlinger, K.A., Craig, T.A., Mehring-Franklin, C.E., DeFreitas, Z. and Hinojosa-Laborde, C. (2013) Antihypertensive Effect of Passion Fruit Peel Extract and its Major Bioactive Components Following Acute Supplementation in Spontaneously Hypertensive Rats. The Journal of Nutritional Biochemistry, 24, 1359-1366. https://doi.org/10.1016/j.jnutbio.2012.11.003

[89] Ajebli, M. and Eddouks, M. (2019) Antihypertensive Activity of Petroselinum crispum through Inhibition of Vascular Calcium Channels in Rats. Journal of Ethnopharmacology, 242, Article ID: 112039. https://doi.org/10.1016/j.jep.2019.112039

[90] de Jesús Ariza-Ortega, T., Zenón-Briones, E.Y., Castrejón-Flores, J.L., Yáñez-Fernández, J., de las Mercedes Gómez-Gómez, Y. and del Carmen, Oliver-Salvador M. (2014) Angiotensin-I-Converting Enzyme Inhibitory, Antimicrobial, and Antioxidant Effect of Bioactive Peptides Obtained from Different Varieties of Common Beans (Phaseolus vulgaris L.) with In Vivo Antihypertensive Activity in Spontaneously Hypertensive Rats. European Food Research and Technology, 239, 785-794. https://doi.org/10.1007/s00217-014-2271-3

[91] Adedapo, A.D.A., Ajayi, A.M., Ekwunife, N.L., Falayi, O.O., Oyagbemi, A., Omobowale, T.O. and Adedapo, A.A. (2020) Antihypertensive Effect of Phragmanthera incana (Schum) Balle on NG-Nitro-L-Arginine Methyl Ester (L-NAME) Induced Hypertensive Rats. Journal of Ethnopharmacology, 257, Article ID: 112888. https://doi.org/10.1016/j.jep.2020.112888

[92] Zhao, W., Yu, J., Su, Q., Liang, J., Zhao, L., Zhang, Y. and Sun, W. (2013) Antihypertensive Effects of Extract from Picrasma quassiodes (D. Don) Benn. in Spontaneously Hypertensive Rats. Journal of Ethnopharmacology, 145, 187-192. https://doi.org/10.1016/j.jep.2012.10.049

[93] Ahmed, Z.B., Yousfi, M., Viaene, J., Dejaegher, B., Demeyer, K., Mangelings, D. and Vander Heyden, Y. (2018) Potentially Antidiabetic and Antihypertensive Compounds Identified from Pistacia atlantica Leaf Extracts by LC Fingerprinting. Journal of Pharmaceutical and Biomedical Analysis, 149, 547-556.

https://doi.org/10.1016/j.jpba.2017.11.049

[94] Chen, Z.-Y., Peng, C., Jiao, R., Wong, Y.M., Yang, N. and Huang, Y. (2009) Anti-hypertensive Nutraceuticals and Functional Foods. Journal of Agricultural and Food Chemistry, 57, 4485-4499. https://doi.org/10.1021/jf900803r

[95] Luna-Vázquez, F., Ibarra-Alvarado, C., Rojas-Molina, A., Rojas-Molina, J., Yahia, E., Rivera-Pastrana, D., Rojas-Molina, A. and Zavala-Sánchez, Á.M. (2013) Nutraceutical Value of Black Cherry Prunus serotina Ehrh. Fruits: Antioxidant and Anti- 
hypertensive Properties. Molecules, 18, 14597-14612. https://doi.org/10.3390/molecules 181214597

[96] do Nascimento, K.F., Moreira, F.M.F., Alencar Santos, J., Kassuya, C.A.L., Croda, J.H.R., Cardoso, C.A.L., do Carmo Vieira, M., Góis Ruiz, A.L.T., Ann Foglio, M., de Carvalho, J.E. and Formagio, A.S.N. (2018) Antioxidant, Anti-Inflammatory, Antiproliferative and Antimycobacterial Activities of the Essential Oil of Psidium guineense Sw. and Spathulenol. Journal of Ethnopharmacology, 210, 351-358.

https://doi.org/10.1016/j.jep.2017.08.030

[97] Jiménez-Ferrer, E., Hernández Badillo, F., González-Cortazar, M., Tortoriello, J. and Herrera-Ruiz, M. (2010) Antihypertensive Activity of Salvia elegans Vahl. (Lamiaceae): ACE Inhibition and Angiotensin II Antagonism. Journal of Ethnopharmacology, 130, 340-346. https://doi.org/10.1016/j.jep.2010.05.013

[98] Hsu, F.-L., Lee, Y.-Y. and Cheng, J.-T. (1994) Antihypertensive Activity of 6-O-Galloyl-D-Glucose, a Phenolic Glycoside from Sapium sebiferum. Journal of Natural Products, 57, 308-312. https://doi.org/10.1021/np50104a019

[99] Lombardo-Earl, G., Roman-Ramos, R., Zamilpa, A., Herrera-Ruiz, M., Rosas-Salgado, G., Tortoriello, J. and Jiménez-Ferrer, E. (2014) Extracts and Fractions from Edible Roots of Sechium edule (Jacq.) Sw. with Antihypertensive Activity. Evidence-Based Complementary and Alternative Medicine, 2014, Article ID: 594326. https://doi.org/10.1155/2014/594326

[100] Simões, L.O., Conceição-Filho, G., Ribeiro, T.S., Jesus, A.M., Fregoneze, J.B., Silva, A.Q.G., Petreanu, M., Cechinel-Filho, V., Niero, R., Niero, H., Tamanaha, M.S. and Silva, D.F. (2016) Evidences of Antihypertensive Potential of Extract from Solanum capsicoides All. in Spontaneously Hypertensive Rats. Phytomedicine, 23, 498-508. https://doi.org/10.1016/j.phymed.2016.02.020

[101] Yamaguchi, S., Matsumoto, K., Koyama, M., Tian, S., Watanabe, M., Takahashi, A., Miyatake, K. and Nakamura, K. (2019) Antihypertensive Effects of Orally Administered Eggplant (Solanum melongena) Rich in Acetylcholine on Spontaneously Hypertensive Rats. Food Chemistry, 276, 376-382. https://doi.org/10.1016/j.foodchem.2018.10.017

[102] Mimaki, Y. (1995) Steroidal Saponins from the Bulbs of Triteleia lactea and Their Inhibitory Activity on Cyclic AMP Phosphodiesterase. Phytochemistry, 38, 1279-1286. https://doi.org/10.1016/0031-9422(94)00790-Z

[103] Ibarrola, D.A., Hellión-Ibarrola, M.C., Montalbetti, Y., Heinichen, O., Campuzano, M.A., Kennedy, M.L., Alvarenga, N., Ferro, E.A., Dölz-Vargas, J.H. and Momose, Y. (2011) Antihypertensive Effect of Nuatigenin-3-O- $\beta$-Chacotriose from Solanum sisymbriifolium Lam. (Solanaceae) (Nuatî Pytâ) in Experimentally Hypertensive (ARH + DOCA) Rats under Chronic Administration. Phytomedicine, 18, 634-640. https://doi.org/10.1016/j.phymed.2011.01.012

[104] Estrada-Soto, S., González-Trujano, Ma.E., Rendón-Vallejo, P., Arias-Durán, L., Ávila-Villarreal, G. and Villalobos-Molina, R. (2021) Antihypertensive and Vasorelaxant Mode of Action of the Ethanol-Soluble Extract from Tagetes lucida Cav. Aerial Parts and Its Main Bioactive Metabolites. Journal of Ethnopharmacology, 266, Article ID: 113399. https://doi.org/10.1016/j.jep.2020.113399

[105] Khan, A.-U. and Gilani, A.H. (2008) Pharmacodynamic Evaluation of Terminalia bellerica for Its Antihypertensive Effect. Journal of Food and Drug Analysis, 16, 6-14. https://doi.org/10.38212/2224-6614.2355

[106] Ahmadvand, H., Khosrobeig, A., Nemati, L., Boshtam, M., Jafari, N., Hosseini, R.H., Pournia, Y., Ahmadvand, H., Khosrobeig, A., Nemati, L., Boshtam, M., Jafari, N., 
Hosseini, R.H. and Pournia, Y. (2012) Rosmarinic Acid Prevents the Oxidation of Low Density Lipoprotein (LDL) in Vitro. Journal of Biological Sciences, 12, 301-307. https://doi.org/10.3923/jbs.2012.301.307

[107] Mihailovic-Stanojevic, N., Belščak-Cvitanović, A., Grujić-Milanović, J., Ivanov, M., Jovović, Dj., Bugarski, D. and Miloradović, Z. (2013) Antioxidant and Antihypertensive Activity of Extract from Thymus serpyllum L. in Experimental Hypertension. Plant Foods for Human Nutrition, 68, 235-240.

https://doi.org/10.1007/s11130-013-0368-7

[108] Gasparotto Junior, A., Gasparotto, F.M., Lourenço, E.L.B., Crestani, S., Stefanello, M.E.A., Salvador, M.J., da Silva-Santos, J.E., Marques, M.C.A. and Kassuya, C.A.L. (2011) Antihypertensive Effects of Isoquercitrin and Extracts from Tropaeolum majus L.: Evidence for the Inhibition of Angiotensin Converting Enzyme. Journal of Ethnopharmacology, 134, 363-372. https://doi.org/10.1016/j.jep.2010.12.026

[109] Perez-Hernandez, N., Ponce-Monter, H., Medina, J.A. and Joseph-Nathan, P. (2008) Spasmolytic Effect of Constituents from Lepechinia caulescens on Rat Uterus. Journal of Ethnopharmacology, 115, 30-35.

https://doi.org/10.1016/j.jep.2007.08.044

[110] Al-Akwaa, A.A., Asmawi, M.Z., Dewa, A. and Mahmud, R. (2020) Antihypertensive Activity and Vascular Reactivity Mechanisms of Vitex pubescens Leaf Extracts in Spontaneously Hypertensive Rats. Heliyon, 6, e04588.

https://doi.org/10.1016/j.heliyon.2020.e04588 